\title{
Sustainability improvement in complex systems composed of products and services
}

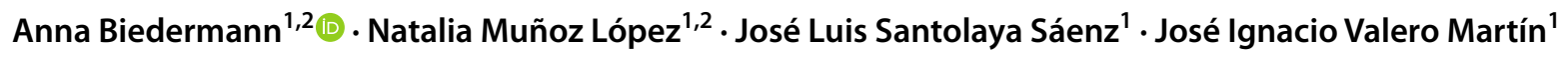

Received: 28 April 2021 / Accepted: 4 December 2021 / Published online: 23 December 2021

(c) The Author(s) 2021

\begin{abstract}
Purpose A wide number of research efforts have been carried out over the last decades to assess and improve system sustainability. Different methods and tools are increasingly implemented in product systems; nevertheless its application to services and other systems, in which products and services are combined, is rather limited. In this work, an approach to improve the sustainability of systems composed of products and services $(\mathrm{P}+\mathrm{S}$ systems) is proposed and implemented in two case studies. Methods The sustainability improvement of $\mathrm{P}+\mathrm{S}$ systems is addressed integrating different methods and approaches. The flows between system approach is used to identify links between all systems involved. The life cycle sustainability assessment (LCSA) method is applied to simultaneously evaluate environmental, economic and social aspects of sustainability with a life cycle perspective. In addition, sustainable design principles are taken into account to propose effective improvement strategies. The systematic development of four phases is required to carry out the integration of these approaches: (i) identification of links between involved systems; (ii) sustainability assessment of the P+S system; (iii) application of sustainability strategies; and (iv) sustainability results comparison.

Results and discussion Two different $\mathrm{P}+\mathrm{S}$ systems are analysed. First, sustainability improvements in the service provided by a clothing boutique are proposed, taking into account that the store where the service is developed and the clothes acquired by the service provider are product systems involved in the service operation. Next, the sustainability of an itinerary exhibition is investigated. Products required for the exhibition space layout as well as the service used to transport all materials between different locations are taken into account. In each case, sustainability indicators obtained in both initial and alternative systems are compared, and variations detected due to strategies applied are analysed.

Conclusions Sustainability of $\mathrm{P}+\mathrm{S}$ systems is evaluated using a set of quantitative indicators, the relative incidence of each system is determined and more sustainable alternatives are projected. Thus, this research supposes an advance towards the sustainable design of complex systems composed of products and services, since effects due to the interconnection between systems are studied and criteria to carry out sustainability-oriented decision making are provided.
\end{abstract}

Keywords Sustainability improvement $\cdot$ Product $\cdot$ Service $\cdot \mathrm{P}+\mathrm{S}$ systems $\cdot$ LCSA $\cdot$ Sustainability strategies $\cdot$ Links between systems

\section{Introduction}

Communicated by Sonia Valdivia

Anna Biedermann

anna@unizar.es

1 Design and Manufacturing Engineering Department, EINA, University of Zaragoza, C/María de Luna 3 (50018), Zaragoza, Spain

2 Member of the, OAAEP Research Group, Financed By the Government of Aragon With FEDER Funds, Zaragoza, Spain
Initiatives to adopt more sustainable approaches have been evolving over the last decades. The sustainability improvement, initially focused on obtaining lower environmental impacts through modifying specific characteristics in the design of individual products (Ryan et al. 1992; Fiksel 1996), has progressively extended towards larger systems, in which sustainability is considered as an holistic challenge (Azapagic et al. 2016; Ceschin 2016). Throughout this progression, the life cycle perspective has become the base of a multitude of concepts and tools to calculate and analyse 
environmental impacts in a system as well as to find solutions that can lead to reducing this impact. ISO standard (ISO 2006) defines the product life cycle as a succession of interconnected stages, beginning from the stage of raw material obtaining in the product creation to end-of-life stage, in which activities of recycling or waste processing are carried out. According to this life-cycle approach, the life cycle assessment (LCA) technique (ISO 2006a, b) was developed to evaluate environmental impacts, and eco-design methodology (Brezet and Van Hemel 1997; Wimmer and Züst 2003) was applied to improve environmental behaviour of product systems.

Applying the sustainable approach not only means taking into account environmental impacts but also introducing socio-ethical principles and models economically feasible. Thus, to assess the sustainability of a system, three dimensions looking simultaneously at economic aspects, environmental issues and social concerns should be considered (WCED 1987; UNCED 1992). According to this approach, the life cycle sustainability assessment (LCSA) methodology (Kloepffer 2008; Finkbeiner et al. 2010) combines three techniques to effectively assess the sustainability of a system: the Environmental Life Cycle Assessment (E-LCA) to examine environmental issues, the Life Cycle Costing (LCC) to evaluate economic aspects and the Social Life Cycle Assessment (S-LCA) to get social impacts. LCSA is based on the same structure of four phases that is already applied in LCA: (i) goal and scope definition; (ii) life cycle sustainability inventory; (iii) life cycle sustainability impact assessment; and (iv) interpreting LCSA results.

In the case of environmental dimension, a number of impact categories are usually considered, and different indicators are used to express environmental impact scores according to individual (midpoint level) or aggregated (endpoint level) characterization (Goedkoop 2013; Huijbregts 2016). Indicators commonly used in LCC calculate the components of life cycle costs but other direct indicators such as annualized costs and the value added from activities, and indicators that apply investment analysis techniques like the internal rate of return, are also used (Wulf et al. 2019). In the case of social impacts, six stakeholder categories (workers, consumers, local community, society, value chain actors and children) are considered by the UNEP's guidelines (UNEP 2020), and different indicators can be used in each category depending on the context of the study. Some initiatives to combine indicators referred to different dimensions have been carried out, e.g. the eco-costs analysis (Vogtlander et al. 2017) and the eco-efficiency indicators, which is the efficiency of economic activities in generating added value from the use of resources (Maxime et al. 2006). In addition, tools to facilitate the communication of global sustainability results have been proposed, e.g. the Life Cycle Sustainability Triangle and the Life Cycle Sustainability Dashboard
(Finkbeiner et al. 2010) as well as different approaches to improve the use and adaptation of the LCSA for scientific application such as the tier approach (Neugebauer et al. 2015).

The LCSA method is considered by numerous authors (Valdivia et al. 2013; Lacasa et al. 2016; Fauzi 2019; Santolaya et al. 2019) as an adequate framework to evaluate impacts in different sustainability dimensions. However, LCSA has been mainly used in product systems and its application to service systems and other systems, in which products and services are combined, is limited. A number of recent investigations, in which the sustainability of a service is studied, are summarized in Table 1 . We can observe that very different activities in both private and public sectors are analysed and comparing different scenarios of alternatives of service operation is a typical objective. For example, (Zheng et al. 2019) study three different alternatives of a pavement maintenance service, and (Arias 2020) analyse both centralized and decentralized wastewater treatment service or (Casson 2020) compare two alternatives of food-street service. Only some stages of the service life cycle are usually analysed. Those activities carried out in the service creation, as well as actions developed when service operation is finished, are almost not taken into account. In addition, results are focused on the environmental dimension while socio-economic data are obtained in very few cases (Nurhadi et al. 2017; Zheng et al. 2019). Thus, more investigations about service systems with a life cycle perspective and including both economic and social indicators are necessary.

As is exposed by Ashford and Hall (2011), products and services are different modes of delivering satisfaction although products, which are generally considered to be material in nature, are substantially different from services, which are generally considered to be immaterial and are consumed right away or very near the time of the market transaction. Both forms of satisfaction involve different actors and some sort of infrastructure (or institutional arrangement) in which the products and services are provided and consequently consumed. From a business development perspective, a wide number of works consider that products and services can be combined with the aim of fulfilling specific consumers' needs and generating value (Boehm and Thomas 2013; UNEP 2015). The resulting systems are denominated as product-service systems (PSS) and suppose a new way of interaction between companies and customers. PSS are integrated solutions of dependent products and services producing a satisfactory utilitarian result. Several categories can be identified: product-oriented services, use-oriented services and result-oriented services (Tukker 2015).

In this work, a wider perspective of combining products and services related with the production and consumption activities is considered. This is based on every product involving some kind of service provision and every service 
is based on the use of several support products (Brezet 2001). Thus, services and products can be treated as parts of larger systems, in which a net of flows and connections between involved systems can be established. These interconnected systems are denominated $\mathrm{P}+\mathrm{S}$ systems in this work. A foreground system (FS) or main system object of study, and background systems (BS) or systems that support FS in different stages of its life cycle, can be recognized (Muñoz et al. 2020). Assessing the sustainability of a system implies defining a suitable functional unit (FU), which characterizes the system performance and allows the adequate communication of sustainability results (Doaulle et al. 2015). In the case of $\mathrm{P}+\mathrm{S}$ systems, in which a FS can be established, FU should be defined taking into account that FS is the main system object of study.

Approaches used by researchers to achieve more sustainable products or services are usually based on Eco-design methods. A broad range of techniques and tools, which could be used in different phases of the product creation process, were already introduced to support the development of more sustainable products (Bovea and Pérez-Belis 2012; Buchert et al. 2014; Andriankaja et al. 2015). The application of sequential phases and the designation of sustainability milestones after completing each phase is a common practice to project more sustainable solutions. (Crul and Diehl 2009) recommend the design for ustainability (D4S) guide to integrate sustainability aspects in the design process of systems. It is supported in four main phases: policy formulation, idea finding, strict development and realization. In addition, impacts associated with each sustainability dimension are considered. (Gagnon et al. 2012) propose the use of the Integrated Sustainable Engineering Design Process (ISEDP) to address the design process of more sustainable systems. This practical approach, supported by life cycle assessment methods, is also introduced by (Santolaya et al. 2019) to project more sustainable products.

Studies dedicated to improve the sustainability of more complex systems are still in early development. With a focus on a satisfaction-based economy, PSS are considered as promising sustainable solutions able to reduce resource consumption. PSS are also understood as means to achieve a circular economy from service-based value propositions (Tukker 2015; Sousa-Zomer and Cauchick 2018; Da 2020). Research works have been initially carried out with the aim of integrating environmental criteria in the PSS design process (Van 2005). Furthermore, methods for the integrated development of products and services (Aurich et al. 2006) and strategies for modelling product-service relationships based on collaborative networks (Sun 2010) have been explored. More recently, socio-ethical issues have been introduced referring to PSS design for sustainability (Vezzoli et al. 2014).
Nevertheless, a wide number of difficulties are found to design, test and implement these systems in which products, services and networks of stakeholders who create, provide or manage the PSS have to be simultaneously considered. On one side, more in-depth studies to solve design challenges associated with fulfilling final customer needs' should be performed. On the other hand, methods integrating complementary approaches are required to address the sustainability of these systems. In particular, the combination of different methods to evaluate and analyse the effects of strategic decisions on the sustainability of connected systems is necessary to project more sustainable solutions.

In this work, an approach integrating different methods is applied to achieve sustainability assessment and project sustainability improvements in $\mathrm{P}+\mathrm{S}$ systems. The methodological framework, on which this research is based, is shown in Fig. 1. On the one hand, the development, implementation and sustainable design of PSS has been reviewed, and problems, such as the interconnectivity of the systems involved, have been addressed. On the other hand, methods to assess sustainability of systems taking into account the life cycle perspective and conventional models of product design and development have been examined. Methodologies such as eco-design, Environmental Design of Industrial Products (EDIP), D4S or ISEDP, applied to obtain more sustainable products and services, have been reviewed. The detailed explanation of the approach applied and results obtained in two different case studies are shown in the following sections.

\section{Methods}

The sustainability improvement of systems composed of products and services interconnected $(\mathrm{P}+\mathrm{S}$ systems) is addressed by integrating different methods and approaches, such as is shown in Fig. 1. Links of multi-compound systems are identified applying the flows between system approach, sustainability of each system involved is evaluated using LCSA method and effective improvement strategies are proposed according to the systematic and logical sequence of engineering design methodology. This integrative approach can be applied to achieve the sustainability improvement of $\mathrm{P}+\mathrm{S}$ systems through the systematic development of four phases (Fig. 2):

\subsection{Phase 1: Identification of links between systems involved}

According to the flows between system approach, a net of connections between product and service systems can be established within a $\mathrm{P}+\mathrm{S}$ system, and two kinds of 


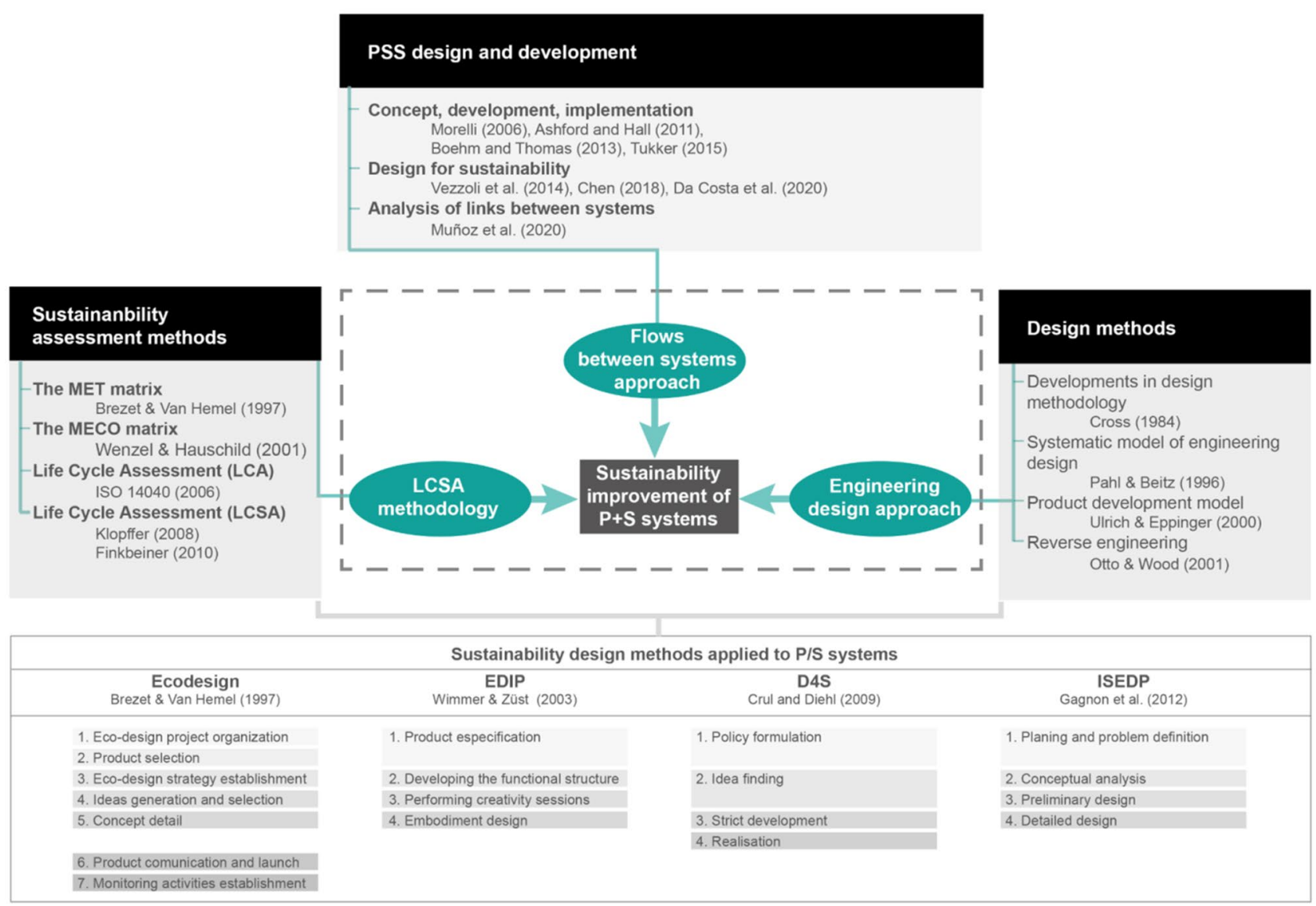

Fig. 1 Methodological framework Integration of different methods and approaches to improve the sustainability of $\mathrm{P}+\mathrm{S}$ systems

systems (FS and BS) can be differentiated. Thus, a $\mathrm{P}+\mathrm{S}$ system is integrated by a bundle of systems, in which a number of BSs are required or generated along the FS life cycle. Three main stages (Creation, Use/Provision, End of life) can be considered in the life cycle of each product/ service system. Links between systems are established, and specific stages of each system are analysed according to the depth and the breadth of the research.

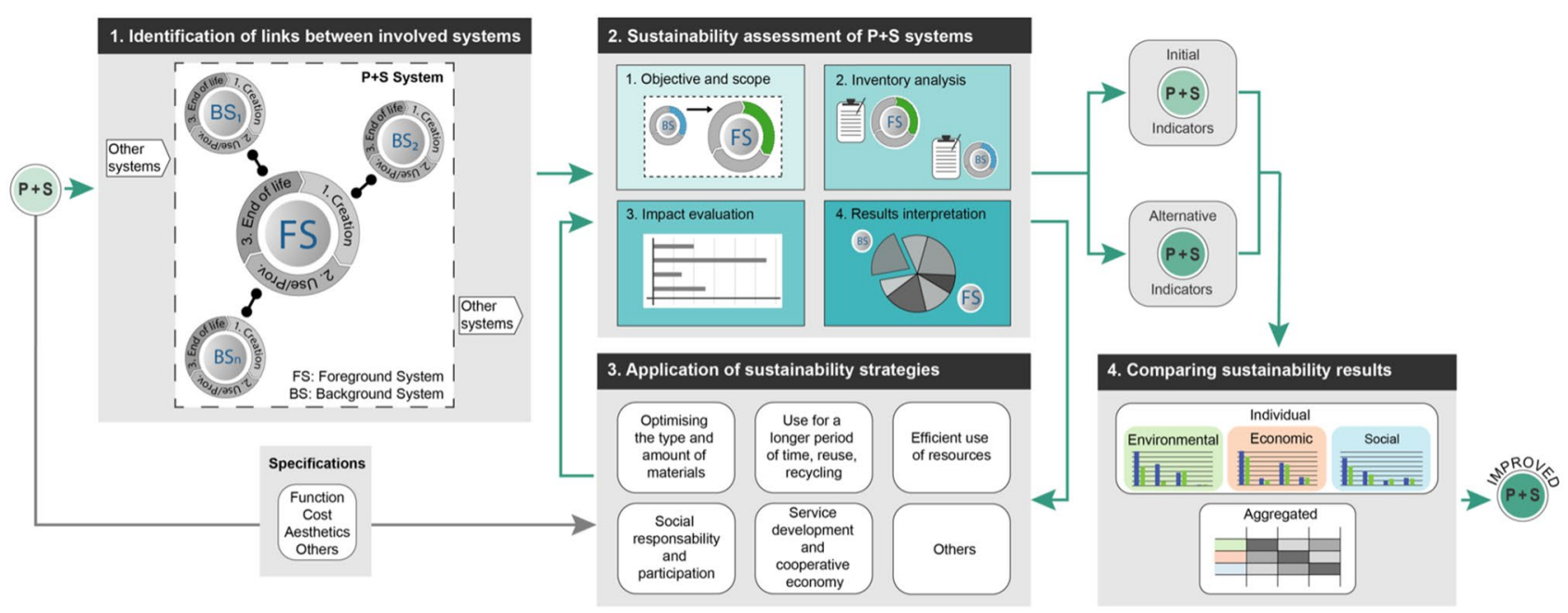

Fig. 2 Phases to improve the sustainability of $\mathrm{P}+\mathrm{S}$ systems 


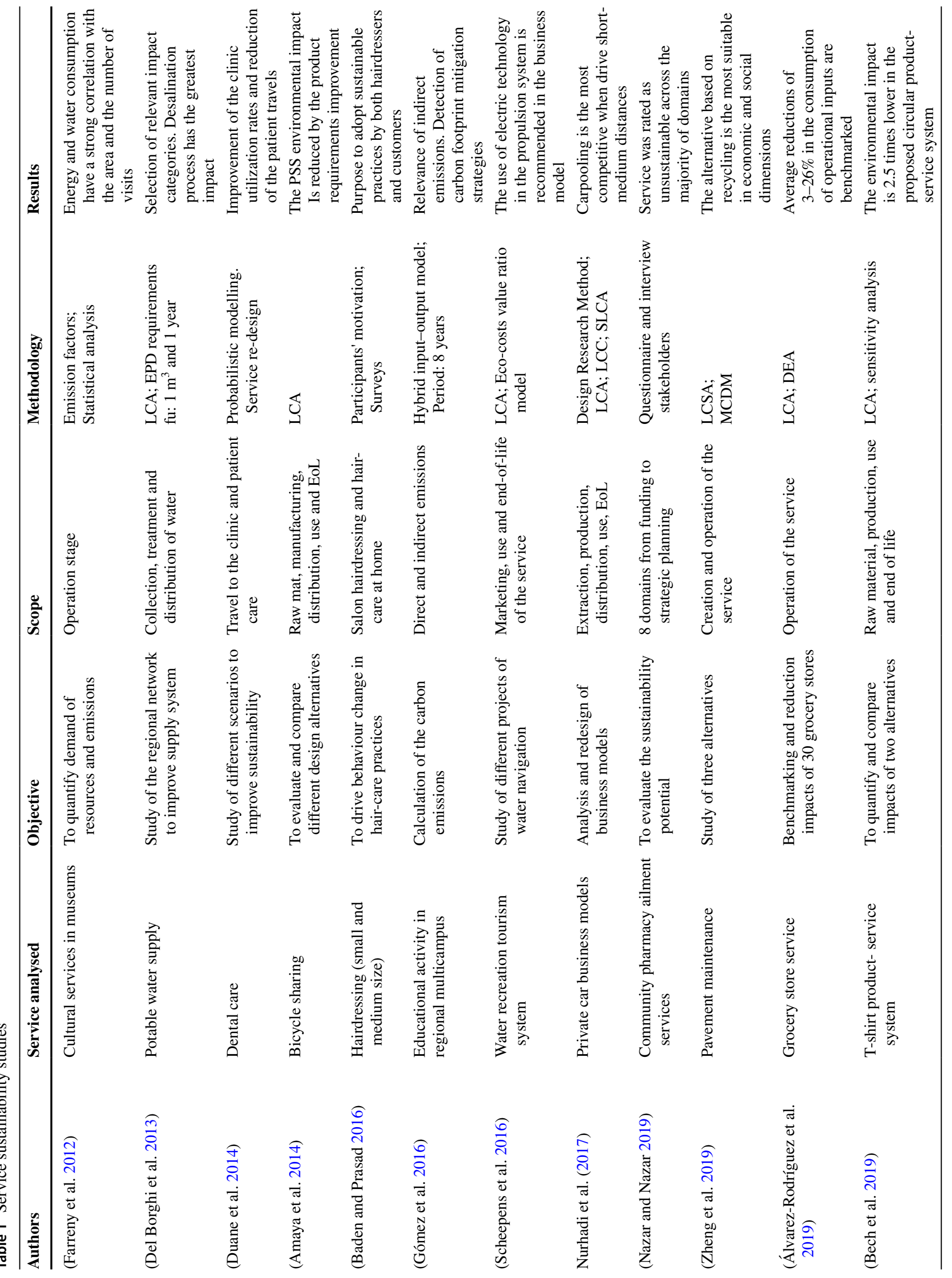




\subsection{Phase 2: Sustainability assessment of the $P+S$ system}

LCSA methodology is applied in four steps. First, the goal and scope are established and FU is determined. Next, inventory data of the initial $\mathrm{P}+\mathrm{S}$ system are obtained through different data collection procedures. Then, environmental, economic and social dimensions are evaluated using a set of suitable indicators. Finally, results are analysed determining the relative incidence of each system and the most significant impact factors.

\subsection{Phase 3: Application of sustainability strategies}

Strategies to improve $\mathrm{P}+\mathrm{S}$ system sustainability should be proposed without compromising initial specifications and taking into account sustainability results obtained in the previous phase. In addition, strategies associated with the improvement of both environmental and socio-economic aspects should be applied. A number of alternatives or scenarios can be analysed in order to reduce the impact of different factors. Sustainability indicators of the alternative $\mathrm{P}+\mathrm{S}$ system are obtained applying LCSA.

\subsection{Phase 4: Comparing sustainability results}

Indicators of the initial and alternative $\mathrm{P}+\mathrm{S}$ systems are compared to detect if improvements have been obtained. The parallel presentation of individual indicators as well as the use of an aggregated sustainability index to obtain a global evaluation can be carried out. In this case, three main methods for weighting indicators can be used: equal weighting, statistic-based weighting and expert opinion-based weighting (OECD 2008; Gan et al. 2017). Weights determined by expert opinion reflect criteria to value each sustainability dimension of stakeholders and trained participants.

To quantitatively evaluate impacts for each sustainability dimension, a set of indicators has been selected in this work. These are defined in Table 2. The environmental dimension is assessed by the global warming potential $\left(\mathrm{GWP}_{100}\right)$ indicator, which represents total emissions of greenhouse gases and the global energy (GE) indicator, which counts energy consumptions due to both electricity and fuels. The total execution costs $\left(\mathrm{C}_{\mathrm{E}}\right)$ to develop an activity and the value added (VA) or net operating profit are used to evaluate the economic dimension. Finally, the workers are selected as the main stakeholders' category, and the social dimension of sustainability is valued by the quantifiable indicators of working time $\left(\mathrm{T}_{\mathrm{W}}\right)$ or time required to carry out an activity and workers salary $\left(\mathrm{S}_{\mathrm{W}}\right)$ that represents labour costs along the activity development.

Specific software and various databases were used to determine sustainability indicators of two different $\mathrm{P}+\mathrm{S}$ 
Table 2 Sustainability indicators used in this work

\begin{tabular}{|c|c|c|c|}
\hline \multicolumn{4}{|l|}{ Environmental dimension } \\
\hline Global warming $\left(\mathbf{G W P}_{\mathbf{1 0 0}}\right)$ & $\left(\mathrm{Kg} \mathrm{CO}_{2}\right.$-eq) & Global energy (GE) & $(\mathrm{MJ})$ \\
\hline \multicolumn{2}{|c|}{$\begin{array}{l}\text { Total emissions of the greenhouse gases computing the radiative forcing } \\
\text { over a time horizon of one hundred years }\end{array}$} & \multicolumn{2}{|c|}{$\begin{array}{l}\text { Energy consumption due to electricity and net calorific value of } \\
\text { fuels }\end{array}$} \\
\hline \multicolumn{4}{|l|}{ Economic dimension } \\
\hline Execution costs $\left(C_{E}\right)$ & $(€)$ & Value added (VA) & $(€)$ \\
\hline \multicolumn{2}{|c|}{$\begin{array}{l}\text { Total cost to execute an activity } \\
\text { It includes costs of materials, processes and other resources }\end{array}$} & \multicolumn{2}{|c|}{$\begin{array}{l}\text { Difference between revenues and costs } \\
\text { It represents the net operating profit obtained from the development } \\
\text { of an activity }\end{array}$} \\
\hline \multicolumn{4}{|l|}{ Social dimension } \\
\hline Working time $\left(\mathrm{T}_{\mathrm{W}}\right)$ & (h) & Workers salary $\left(\mathbf{S}_{\mathrm{W}}\right)$ & $(€)$ \\
\hline \multicolumn{2}{|c|}{$\begin{array}{l}\text { Time developing an activity } \\
\text { It depends on the times consumed and resources used in each task car- } \\
\text { ried out in the activity }\end{array}$} & \multicolumn{2}{|c|}{$\begin{array}{l}\text { Salary of the workers involved in the development of an activity } \\
\text { It also represents labour costs }\end{array}$} \\
\hline
\end{tabular}

systems, in which the service provided by a clothing boutique and the development of an itinerary exhibition are, respectively, the main system objects of study. Being as different product and service systems are combined in each case study, a lot of data types need to be managed. In the case of the clothing boutique, environmental as well as socioeconomic data of the store in which the service is provided were obtained using the Cype software (usually applied in construction projects), and the database of the International Environmental Product Declarations (EPD) System was used to obtain energy consumptions and greenhouse gas emissions along the clothes manufacturing process.

In the case of the itinerant exhibition, the CEX software was applied to evaluate energy consumptions in heating and cooling processes associated with the service development in each destination, and the emission factors of electric commercial companies (Mapama 2018) were used to evaluate greenhouse gas emissions from both electric and fuel consumptions. A truck-based transport service was considered to move the materials exhibited between destinations. In addition, $\mathrm{GaBi}$ ts 9.2 software (Education (EPD 2020) and ProBas (v.1.5.5) database (UBA 2007) were used to obtain environmental indicators of different materials and products; data on construction and demolition waste management in recycling plants operating in Spain were consulted in (Villoria 2014), and, finally, working times and workers' salaries were determined in accordance with the International Trade Union Confederation (ITUC 2016).

\section{Case studies}

Two different $\mathrm{P}+\mathrm{S}$ systems, in which FS are, respectively, a service dedicated to selling clothes in the centre of a big city and a cultural service, in which historical themes are temporarily exhibited in different destinations, are analysed.
In each case, a more sustainable $\mathrm{P}+\mathrm{S}$ system is projected applying the four phases previously exposed.

\subsection{Case 1. Clothing boutique}

First, the case of a clothing boutique, in which personalized attention to customers is provided and high quality garments are sold, is the object of study. Service is provided by only two workers, and people with a medium-high purchasing power are usual customers.

\subsubsection{Identification of links between systems involved}

Sustainability study is addressed taking into account that service provision in the clothing boutique is identified as FS and the store, in which the service is operated and the clothes acquired by the service provider are product systems involved in the service development. These are designated, respectively, $\mathrm{BS}_{1}$ and $\mathrm{BS}_{2}$ (Fig. 3). Construction and dismantling processes of the clothing store are, respectively, studied in the creation and end of life stages of the service life cycle. In addition, the clothes production process is considered. The distribution system from the textile industry to the clothing boutique is not included within this research. FU is a customer visit in which clothes are acquired.

\subsubsection{Sustainability assessment of the $P+S$ system}

A detailed study of the service performance was carried out in order to obtain inventory data. Service is provided by two workers, each one working $38.5 \mathrm{~h}$ weekly. Their activities were classified into the following groups: clothes preparation (reception and unpacking of the articles provided from the textile industry, classification, labelling and ironing of the garments received), exhibition and storage, test and fix of clothes (individual attention to customers to select the most 
Fig. 3 Case 1: Clothing boutique. Scheme of systems involved

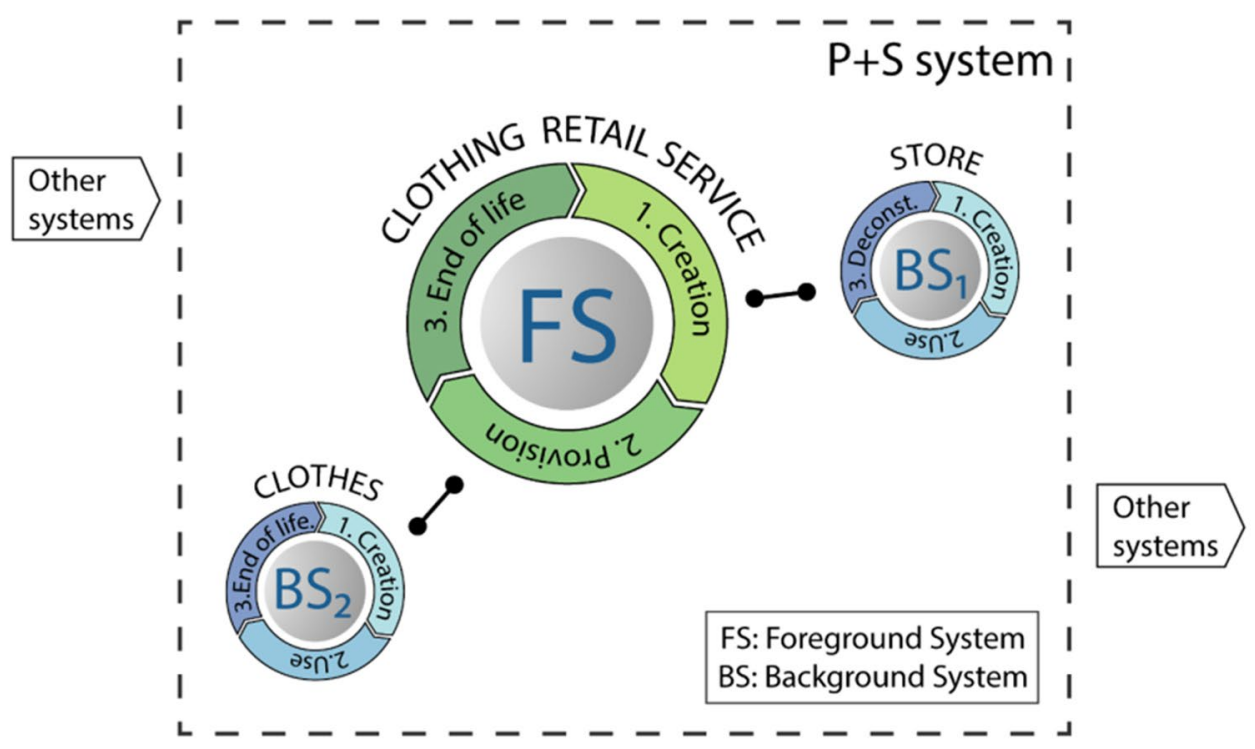

suitable clothes), sale with customer charge and packaging, and other activities such as cleaning and service management. Data of materials used as well as energy consumptions by different equipment were collected over 1 year. In addition, the working times in each activity were estimated and the costs associated with the service operation were obtained. Operational costs included clothing acquisition costs, labour, consumable (materials used in packaging, stitching or cleaning activities as well as energy consumptions) and indirect costs (insurance and rent payments and clothes, energy and consumables taxes). All data, expressed per customer visit, are summarized in Table 3. A total of 336 visits were quantified during the reference year.

Two clothing collections (winter and summer) of approximately 800 items each one are bought each year by the service provider. The EPD database and ITUC Report were reviewed to obtain clothes manufacture data. In addition, data of the type of clothes sold (upper parts or lower parts) and their distribution of material compositions were gathered for a period of 1 month (approx. 106 pieces). The most similar upper and lower parts available in EPD to the most representative clothes sold in the boutique were selected. The EPD for ISKO26632 item finished denim fabric jeans, which are made of 50\% cotton fibre, 5-25\% man-made fibres and $40 \%$ regenerated fibres, was applied to half of the clothes procured, and the EPD for t-shirt $7046 \mathrm{THV}$, which are made of $45 \%$ polyester and $55 \%$ cotton, was applied to the other half of clothes The materials obtaining and manufacturing processes were considered. The raw materials extraction stage of jeans includes harvesting of cotton, extraction of man-made fibres, processing into warp and weft yarns and extraction and production of the chemicals. The manufacturing processes include the transport of raw materials to the factory, clothes production, impacts generated by fuel burned, impacts due to the electricity burned, impacts due to the electricity production and transport within the production plant. On the other hand, the raw material extraction stage of $\mathrm{t}$-shirts is referred to production of fibres, pre-treatments and production of other materials like packaging and the manufacturing processes stage involves the transport to the factory, spinning, knitting, assembly and packaging of clothes. The execution costs of both trousers and t-shirts are referred to material costs, overhead costs and workers salary.

The transformation of an empty space into a properly equipped store of $65.3 \mathrm{~m}^{2}$ was conducted in the service creation stage. Different materials were used, and a set of construction activities was developed. Standard EN 15804:2012 + A2:2019 (2019) was applied to establish the life cycle phases of the construction product. Therefore, phases referred to the extraction of raw material, transport and manufacture, as well as those related with the transport of materials to the construction site and final construction or installation activities, were taken into account as part of the store creation stage. Data of materials needed, energy consumptions, execution costs and labour times along the store construction process were obtained by means of Cype software. A summary of these data, classified into six groups of activities (facades, partitions, facilities, coatings, furniture and others), is presented in Table 3.

In addition, the store dismantling was considered after 10 years of service operation. The following phases were analysed: deconstruction process, onsite waste segregation, transport and appropriate management of different waste categories. Wastes were classified in three main groups: stone, non-stone and potentially hazardous. The determination of costs associated with waste management was carried out based on the work of (Villoria 2014), in which different costs of segregation, transport 


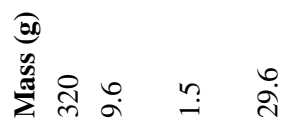

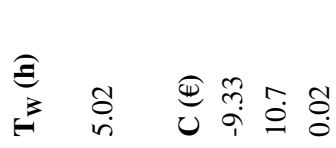

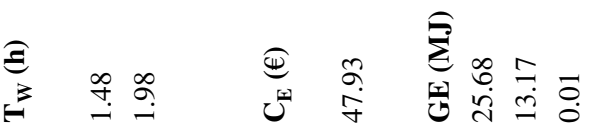

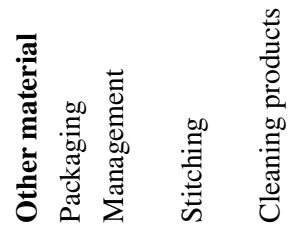

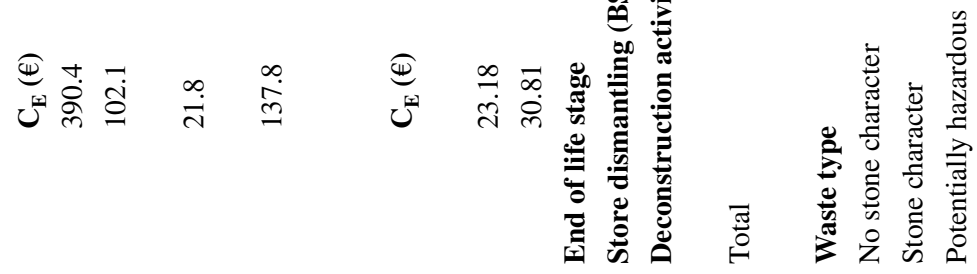

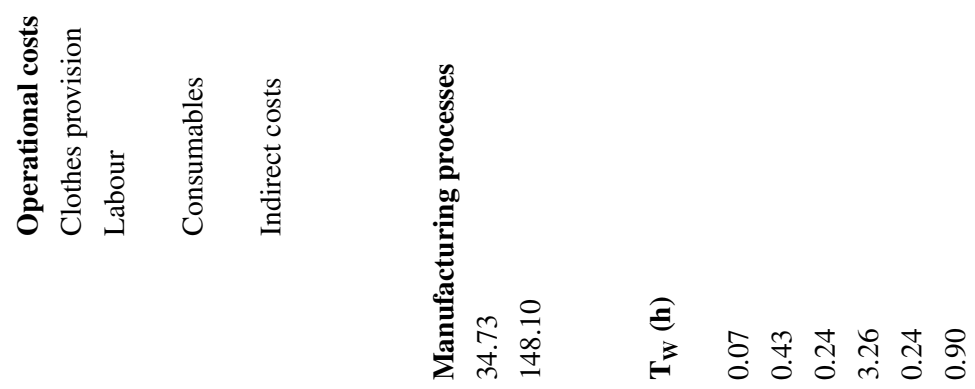

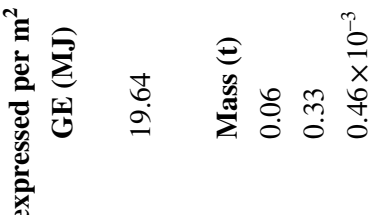

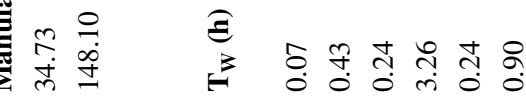

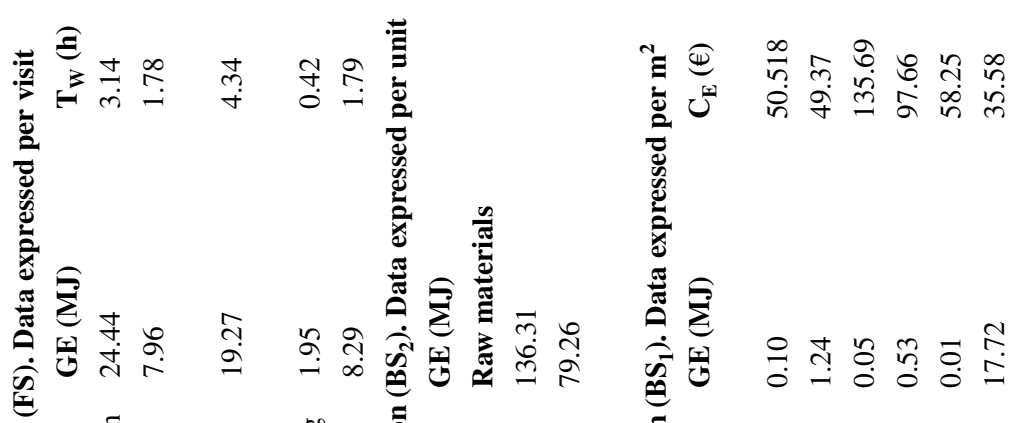

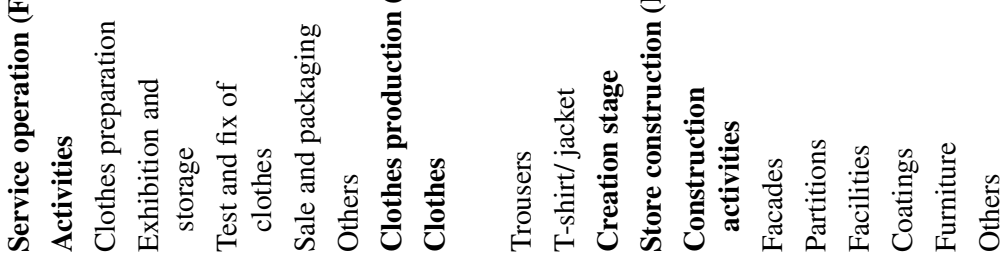


to the recycling plant and deposition activities are evaluated depending on the volume of material managed. In this case, waste separation in origin fulfilling RD105/2018 and transport to the recycling plant assuming a distance of 5-10 km from the worksite were considered. Data of mass, energy consumptions and costs according to type of waste are summarized in Table3.

Sustainability was evaluated using the indicators previously defined in Table 2. Data obtained, expressed per customer visit, are shown in Table 4. Indicators of the $\mathrm{P}+\mathrm{S}$ system are obtained as the sum of those calculated in each involved system. Values of $31.86 \mathrm{KgCO}_{2}$-eq and $690.68 \mathrm{MJ}$ are, respectively, obtained for the $\mathrm{GWP}_{100}$ and GE indicators. Service operation, store construction and clothes production generate total costs of $399.52 €$ and global VA of $106.17 €$. If the social dimension is reviewed, accumulated working times and salaries by the service providers and workers required in store construction and clothes manufacture are, respectively, $18.25 \mathrm{~h}$ and $134.04 €$. Reviewing the sustainability indicators of the store $\left(\mathrm{BS}_{1}\right)$ and clothes $\left(\mathrm{BS}_{2}\right)$ systems, we observe that their relative contribution to the $\mathrm{P}+\mathrm{S}$ indicators is notably different. A total service operation time of 10 years is considered using $\mathrm{BS}_{1}$. Thus, the relative incidence of the store system is much smaller. We can also observe that $\mathrm{BS}_{2}$ causes high environmental impact and FS activities generate high social indicators.

Figure 4 shows the relative incidence of each system on the $\mathrm{P}+\mathrm{S}$ sustainability indicators. The percentage distribution of $\mathrm{GWP}_{100}, \mathrm{C}_{\mathrm{E}}$ and $\mathrm{T}_{\mathrm{w}}$ is, respectively, represented in Figs. $4 \mathrm{a}, \mathrm{b}$ and $\mathrm{c}$. In addition, the FS incidence is broken down into different factors. It is observed that greenhouse gas emissions due to clothes manufacture accounts for $82.2 \%$ of the total $\mathrm{P}+\mathrm{S}$ emissions and are much higher than those due to consumables, electricity consumption $(9.4 \%)$ and construction/dismantling of the store (8.4\%). In addition, costs referred to indirect costs and labour in FS are, respectively, 39.9 and $28.9 \%$ of the total $\mathrm{P}+\mathrm{S}$ costs and are higher than those due to clothes manufacture (23.5\%) and construction/dismantling of the store (2.3\%). While, if $\mathrm{T}_{\mathrm{w}}$ indicator is reviewed, we observe that clothes manufacture accounts for $36.2 \%$ of the accumulated working time but activities carried out along the service provision as testing and fixing of clothes (23.9\%), clothes preparation (17.2\%) and exhibition and storage (9.8\%) have also significant incidence in this social indicator.

\subsubsection{Application of sustainability strategies}

Different sustainability strategies, which do not compromise the initial FS specifications, are proposed. First, a strategy to reduce the incidence of the most relevant impact factor in the $\mathrm{P}+\mathrm{S}$ system is suggested. Hence, the amount of clothes acquired to the textile industry by the service provider is reviewed. Since each year approximately $20 \%$ of the initial merchandize supplied from the textile industry is not sold and must be marketed in other ways, a decrease of $10 \%$ on articles acquired in each clothing collection (a total of 80 items) is planned. This strategy is designated Str1. Next, some changes in furniture design and distribution are projected in order to reduce the working time of the service providers in activities such as the exhibition and storage of clothes. These changes are shown in Fig. 5, in which both the usual route made by the workers to move clothes from the storage area upstairs to the point of sale (Fig. 5a) and the new boutique design are exposed (Fig. 5b). The use of furniture without doors or drawers is proposed to facilitate the clothes exhibition, and the use of three different heights is planned to reduce the number of trips from the storage area for the service providers. This strategy is named Str2.

Inventory analysis and subsequent sustainability assessment, was carried out applying each of these strategies. The resulting sustainability indicators, expressed per customer visit, are summarized in Table 5. It can be noted that Str1 affects the impact of $\mathrm{BS}_{2}$ and $\mathrm{Str} 2$ affects the impact of $\mathrm{BS}_{1}$, but also both strategies affect sustainability indicators of FS, due to the links between systems. At the same time, significant variations are detected in the indicators of the $\mathrm{P}+\mathrm{S}$ system.

Str1 considerably affects the $\mathrm{BS}_{2}$ impact so that indicators of this system reduce $10 \%$. In addition, significant changes are noted in FS since a lower number of clothes have to be prepared, classified or ironed along the service operation. Relative reductions of 5.5 and $1.8 \%$ are obtained in environmental indicators of FS. A substantial improvement of VA is also calculated due to the reduction in the number of clothes acquired by the service provider and, consequently,
Table 4 Case 1: Clothing boutique Sustainability indicators of the initial $\mathrm{P}+\mathrm{S}$ system (data expressed per visit)

\begin{tabular}{|c|c|c|c|c|c|c|}
\hline \multirow[b]{2}{*}{$\begin{array}{l}\text { Initial } \\
\text { system }\end{array}$} & \multicolumn{2}{|c|}{ Environmental dimension } & \multicolumn{2}{|c|}{ Economic dimension } & \multicolumn{2}{|c|}{ Social dimension } \\
\hline & $\begin{array}{l}\mathrm{GWP}_{100} \\
\left(\mathrm{Kg} \mathrm{CO}_{2} \text {-eq }\right)\end{array}$ & $\begin{array}{l}\text { GE } \\
(\mathrm{MJ})\end{array}$ & $\begin{array}{l}\mathrm{C}_{\mathrm{E}} \\
(€)\end{array}$ & $\begin{array}{l}\text { VA } \\
(€)\end{array}$ & $\begin{array}{l}\mathrm{T}_{\mathrm{W}} \\
\text { (h) }\end{array}$ & $\begin{array}{l}S_{W} \\
(€)\end{array}$ \\
\hline (FS) Service & 2.74 & 62.04 & 261.77 & 100.48 & 11.49 & 85.67 \\
\hline$\left(\mathrm{BS}_{1}\right)$ Store & 2.22 & 25.92 & 9.25 & 0.55 & 0.16 & 2.77 \\
\hline$\left(\mathrm{BS}_{2}\right)$ Clothes & 26.90 & 602.72 & 128.50 & 5.14 & 6.59 & 45.60 \\
\hline $\mathbf{P}+\mathbf{S}$ & 31.86 & 690.68 & 399.52 & 106.17 & 18.25 & 134.04 \\
\hline
\end{tabular}




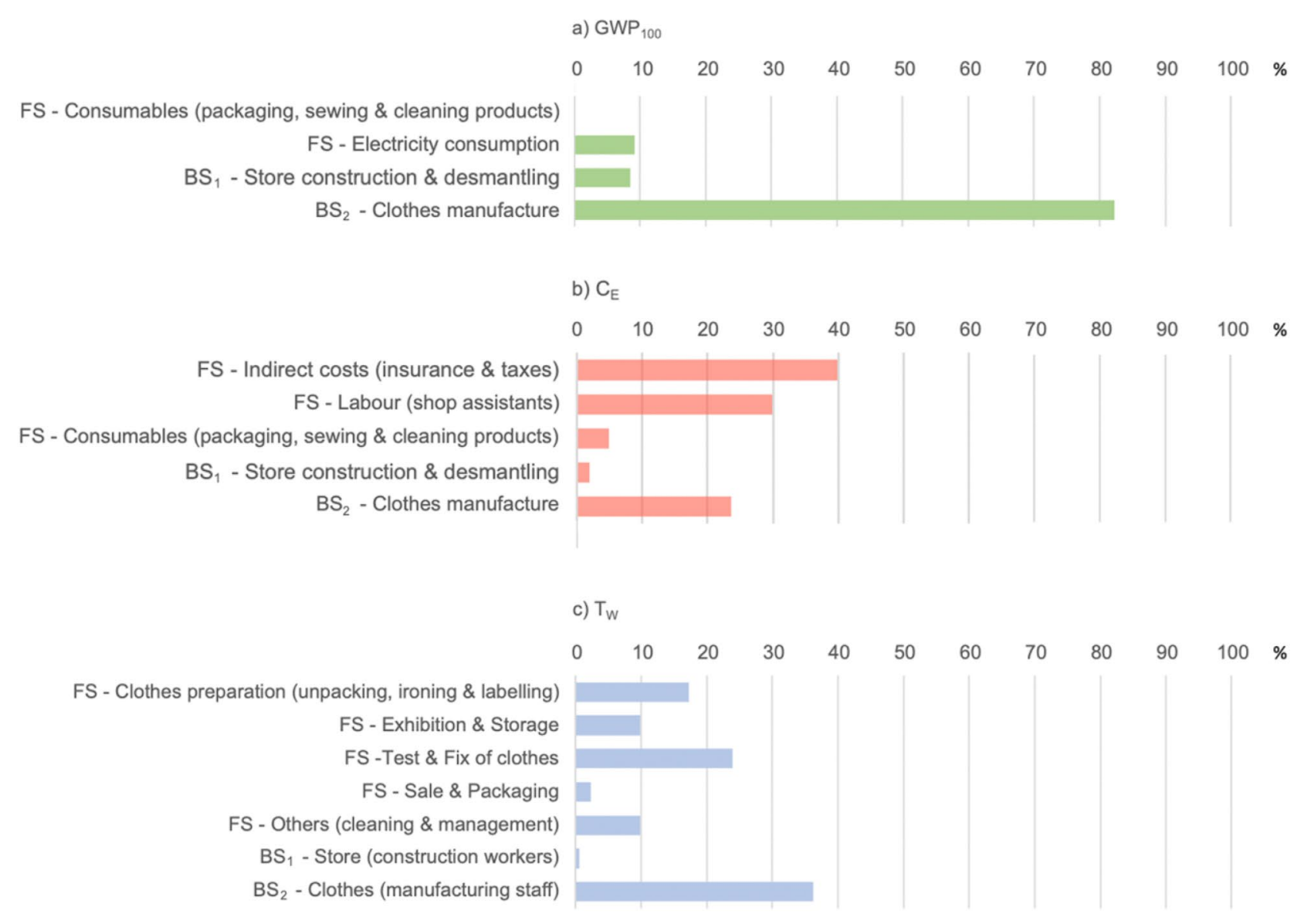

Fig. 4 Case 1: Clothing boutique. Percentage distribution of factors affecting sustainability indicators of the initial $\mathrm{P}+\mathrm{S}$ system

in clothing acquisition costs. The relative variations of sustainability indicators in each system give rise to significant variations in the indicators of the $\mathrm{P}+\mathrm{S}$ system. Environmental indicators reduce around $8.9 \%$. In the economic dimension, $\mathrm{C}_{\mathrm{E}}$ reduces $5.7 \%$ and VA increases $45.8 \%$. While, in the social dimension $\mathrm{T}_{\mathrm{w}}$ and $\mathrm{S}_{\mathrm{w}}$ indicators reduce, respectively, 6.3 and 3.4\%. On the other hand, Str 2 increases the $\mathrm{BS}_{1}$ impact since some reforms have to be implemented in the clothing store, but supposes that $\mathrm{T}_{\mathrm{w}}$ indicator of FS can be improved, since exhibition and storage activities can be facilitated through suitable changes in furniture design and distribution. The increase of the $\mathrm{BS}_{1}$ indicators does not exceed $2 \%$, while the $\mathrm{T}_{\mathrm{w}}$ indicator of $\mathrm{FS}$ reduces around $1 \%$. The small variations estimated in the sustainability indicators of each system also cause very small changes $(<0.1 \%)$ in the indicators of the $\mathrm{P}+\mathrm{S}$ system.

It is considered that strategies 1 and 2 could be shortterm implemented taking into account the current operation of the service. Another type of strategy could be planned if the service operation was transferred to another location. In particular, the incidence of materials and activities with high impact in the construction process of the store system could be reviewed. For example, the replacement of the silicate paint by limewash can be projected in the coating activities.

\subsubsection{Comparing sustainability results}

First, a parallel presentation of sustainability indicators is carried out in Fig. 6. The percentage variations obtained in each involved system are shown, taking into account that both sustainability strategies are applied. Significant improvements in the indicators of the $\mathrm{P}+\mathrm{S}$ system are found. If environmental indicators are reviewed, reductions of $8.8 \%$ are obtained, due mainly to the application of strategy 1 , which affects environmental impact of $\mathrm{BS}_{2}$ (decrease of $8.4 \%$ ). In the economic dimension, execution costs are reduced in $\mathrm{FS}$ and $\mathrm{BS}_{2}$ when strategy 1 is applied (2.53 and 3.22\%, respectively). Costs increase due to the application of the strategy 2 but this is relatively small $(0.01 \%)$. A reduction of $5.7 \%$ is finally obtained in the $\mathrm{C}_{\mathrm{E}}$ indicator. The substantial improvement of VA indicator is mainly due the fact that the clothes acquisition costs are reduced due to the application of Str1, while it is considered that revenues can be maintained in FS. An increase of $45.8 \%$ is obtained in the VA indicator. Significant variations are also detected in social indicators. 
Fig. 5 Case 1: Clothing boutique. Applying the sustainability strategy 2 (a) Usual route of the service providers within the store. (b) Changes in furniture design a)

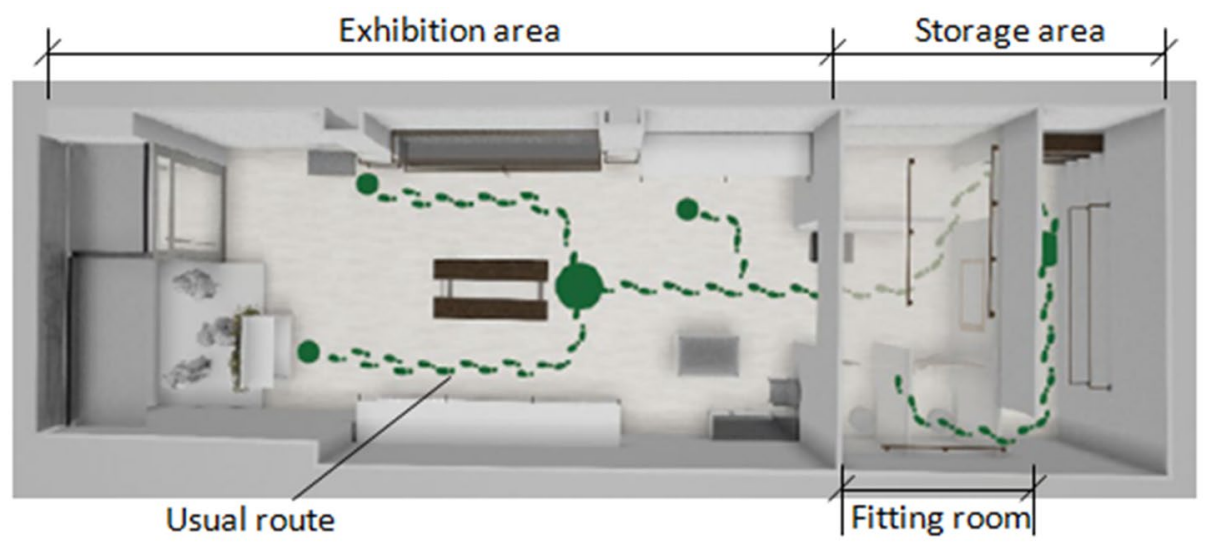

b)

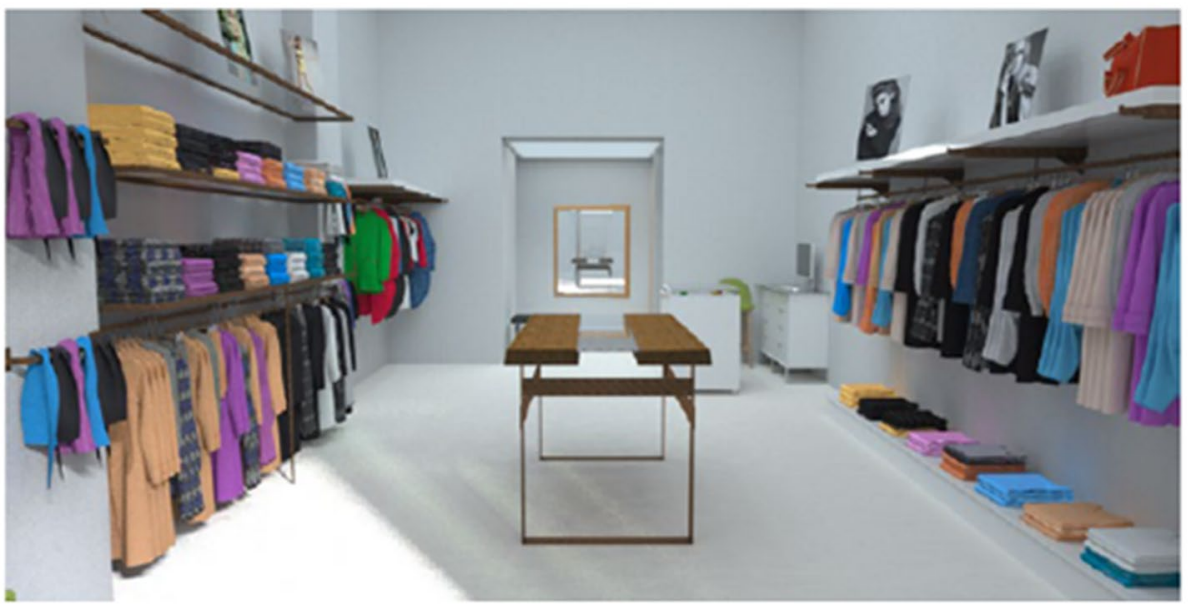

The application of both sustainability strategies supposes that $\mathrm{T}_{\mathrm{W}}$ of the $\mathrm{P}+\mathrm{S}$ system reduces $6.9 \%$ and, particularly, a positive effect is achieved in the working time of service providers, which reduces $3.3 \%$. However, a reduction is also detected in the $\mathrm{S}_{\mathrm{W}}$ indicator since a smaller number of clothes are manufactured applying the strategy 1 .
Table 5 Case 1: Clothing boutique Sustainability indicators of the $\mathrm{P}+\mathrm{S}$ system applying sustainability strategies (data expressed per visit)

\begin{tabular}{|c|c|c|c|c|c|c|}
\hline & \multicolumn{2}{|c|}{ Environmental dimension } & \multicolumn{2}{|c|}{ Economic dimension } & \multicolumn{2}{|c|}{ Social dimension } \\
\hline & $\begin{array}{l}\mathrm{GWP}_{100} \\
\left(\mathrm{Kg} \mathrm{CO}_{2} \text {-eq) }\right.\end{array}$ & $\begin{array}{l}\text { GE } \\
(\mathrm{MJ})\end{array}$ & $\begin{array}{l}\mathrm{C}_{\mathrm{E}} \\
(€)\end{array}$ & $\begin{array}{l}\text { VA } \\
(€)\end{array}$ & $\begin{array}{l}\mathrm{T}_{\mathrm{W}} \\
(\mathrm{h})\end{array}$ & $\begin{array}{l}S_{W} \\
(€)\end{array}$ \\
\hline & \multicolumn{6}{|l|}{ Strategy 1} \\
\hline (FS) Service & 2.59 & 60.92 & 251.65 & 149.64 & 11 & 85.67 \\
\hline$\left(\mathbf{B S}_{1}\right)$ Store & 2.22 & 25.92 & 9.25 & 0.55 & 0.17 & 2.77 \\
\hline$\left(\mathrm{BS}_{2}\right)$ Clothes & 24.21 & 542.45 & 115.65 & 4.63 & 5.93 & 41.04 \\
\hline \multirow[t]{2}{*}{$\mathbf{P}+\mathbf{S}$} & 29.02 & 629.29 & 376.55 & 154.82 & 17.10 & 129.48 \\
\hline & \multicolumn{6}{|l|}{ Strategy 2} \\
\hline (FS) Service & 2.74 & 62.04 & 261.77 & 100.48 & 11.37 & 85.67 \\
\hline$\left(\mathrm{BS}_{1}\right)$ Store & 2.24 & 26.08 & 9.28 & 0.56 & 0.17 & 2.80 \\
\hline$\left(\mathrm{BS}_{2}\right)$ Clothes & 26.90 & 602.72 & 128.50 & 5.14 & 6.59 & 45.60 \\
\hline \multirow[t]{2}{*}{$\mathbf{P}+\mathbf{S}$} & 31.88 & 690.84 & 399.55 & 106.18 & 18.13 & 134.07 \\
\hline & \multicolumn{6}{|c|}{ Strategy $1+$ Strategy 2} \\
\hline (FS) Service & 2.59 & 60.92 & 251.65 & 149.64 & 10.88 & 85.67 \\
\hline$\left(\mathbf{B S}_{1}\right)$ Store & 2.24 & 26.08 & 9.28 & 0.56 & 0.17 & 2.80 \\
\hline$\left(\mathrm{BS}_{2}\right)$ Clothes & 24.21 & 542.45 & 115.65 & 4.63 & 5.93 & 41.04 \\
\hline $\mathbf{P}+\mathbf{S}$ & 29.04 & 629.45 & 376.58 & 154.82 & 16.98 & 129.51 \\
\hline
\end{tabular}




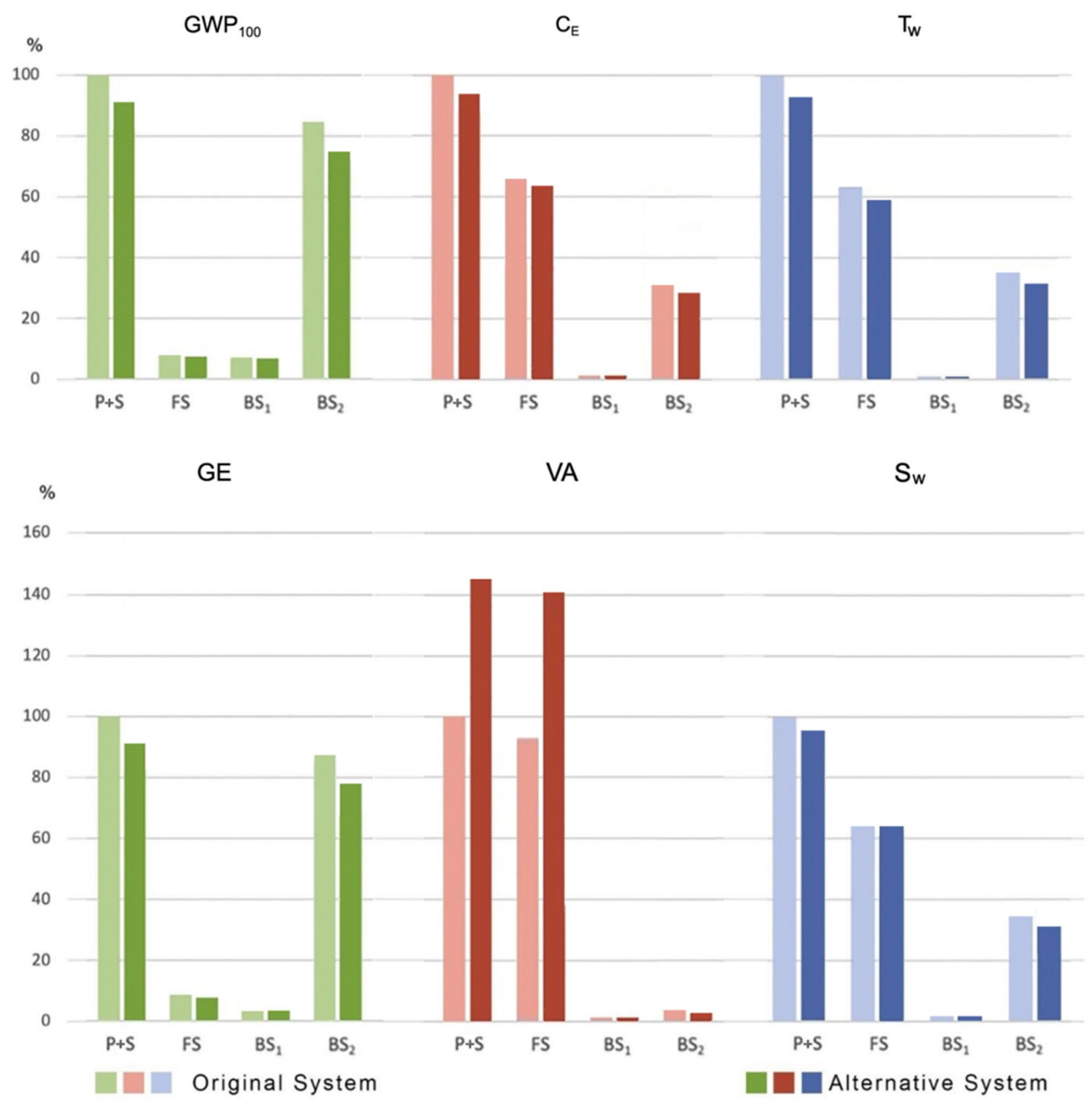

Fig. 6 Case 1: Clothing boutique Comparing sustainability indicators of the initial and alternative $\mathrm{P}+\mathrm{S}$ systems

In order to obtain a global sustainability evaluation taking into account indicators of each dimension, an aggregated index is calculated. Four cases are analysed according to the following assumptions: $\mathrm{C} 1$, equal importance of each sustainability dimension, and $\mathrm{C} 2-4$, one sustainability dimension is set as dominant and equal importance is suggested to the rest. A weight of 0.5 is allocated to the dominant dimension, and 0.25 is assigned to the other two dimensions. The global sustainability improvement index is calculated by weighting the percentage variation of the indicators calculated for each sustainability dimension. Both, percentage variation of each indicator and global sustainability improvement index, are calculated in the cases where Str1 and Str2 are individually applied as well as if the two strategies are combined. Results obtained are shown in Table 6.

In all cases, a positive result is obtained for the global sustainability improvement index. Thus, strategies proposed are considered effective to improve the sustainability of the $\mathrm{P}+\mathrm{S}$ system. It can be noted that Str1 provides 
Table 6 Case 1: Clothing boutique Sustainability improvement of the $\mathrm{P}+\mathrm{S}$ system applying sustainability strategies

\begin{tabular}{|c|c|c|c|c|c|c|c|c|c|}
\hline & \multicolumn{2}{|c|}{ Envir. dimension } & \multicolumn{2}{|c|}{ Econ. dimension } & \multicolumn{2}{|c|}{$\begin{array}{l}\text { Social } \\
\text { dimension }\end{array}$} & & & \\
\hline & $\mathrm{GWP}_{100}$ & GE & $\mathrm{C}_{\mathrm{E}}$ & VA & $\mathrm{T}_{\mathrm{W}}$ & $\mathrm{S}_{\mathrm{W}}$ & \multicolumn{3}{|c|}{$\begin{array}{l}\text { Sustainability improvemen } \\
(\%)\end{array}$} \\
\hline & \multicolumn{6}{|c|}{ Weight coefficient } & Str1 & Str2 & Str $1+\operatorname{Str} 2$ \\
\hline $\mathrm{C} 1$ & 0.166 & 0.166 & 0.166 & 0.166 & 0.166 & 0.166 & 12.05 & 0.10 & 12.14 \\
\hline $\mathrm{C} 2$ & 0.25 & 0.25 & 0.125 & 0.125 & 0.125 & 0.125 & 11.26 & 0.06 & 11.32 \\
\hline $\mathrm{C} 3$ & 0.125 & 0.125 & 0.25 & 0.25 & 0.125 & 0.125 & 15.48 & 0.07 & 15.55 \\
\hline \multirow[t]{2}{*}{$\mathrm{C} 4$} & 0.125 & 0.125 & 0.125 & 0.125 & 0.25 & 0.25 & 9.40 & 0.16 & 9.55 \\
\hline & \multicolumn{6}{|c|}{ Variation of indicators in the $P+S$ system $(\%)$} & & & \\
\hline Str1 & 8.92 & 8.88 & 5.75 & 45.81 & 6.31 & -3.4 & & & \\
\hline Str2 & -0.06 & -0.02 & -0.008 & 0.006 & 0.64 & -0.02 & & & \\
\hline Str1 + Str2 & 8.86 & 8.86 & 5.74 & 45.82 & 6.95 & -3.38 & & & \\
\hline
\end{tabular}

a higher percentage of improvement than Str2. In addition, Str 2 generates a positive result in the $\mathrm{P}+\mathrm{S}$ system, particularly in the case in which social dimension is more important. The positive effect in FS of this strategy balances the negative impact of $\mathrm{BS}_{1}$. If both strategies are combined, the highest sustainability improvement (15.5\%) is obtained in C3 (economic dimension has the highest weight coefficient).

\subsection{Case 2. Itinerary exhibition}

In this case, the sustainability of an itinerary exhibition, in which historical contents are exposed, is the object of study. After its inauguration in Madrid, the exhibition will travel to seven different European destinations (Valencia, Lyon, Luxembourg, Munich, Zurich, Turin and Barcelona), staying for 6 months in each of them.

\subsubsection{Identification of links between systems}

The development of this cultural service (FS) is supported by the contents to exhibit as well as by those elements used in the suitable transformation of a total area of approximately $2500 \mathrm{~m}^{2}$, in which exhibition will be carried out. A transport service to move materials between destinations is also required. Exhibition space layout and transport service are designated, respectively, $\mathrm{BS}_{1}$ and $\mathrm{BS}_{2}$ in this $\mathrm{P}+\mathrm{S}$ system (Fig. 7). The manufacture of artefacts, showcases and audiovisual content used in the itinerary exhibition are not included within this research. FU is a visit to the exhibition.

\subsubsection{Sustainability assessment of the $P+S$ system}

Inventory has been carried out using primary data collected during the creation, provision and end of life stages
Fig. 7 Case 2: Itinerary exhibition. Scheme of systems involved

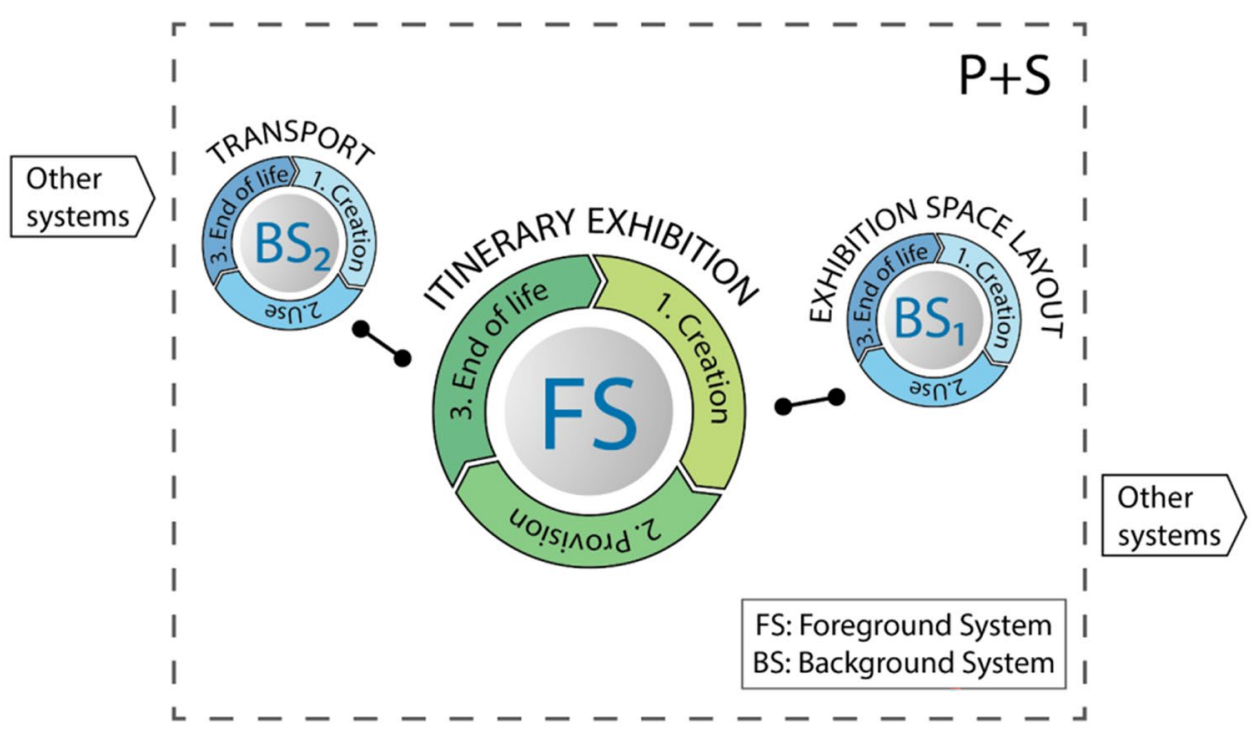


of the exhibition in the first destination (Table 7). The exhibition is open every day for $11 \mathrm{~h}$ during 6 months. Activities of ticketing, public attention, coordination, gift shop and cloakroom are developed in two shifts of $5.5 \mathrm{~h}$ each day. The security of the exhibition is organized in three shifts of $8 \mathrm{~h}$ ( 3 workers in each one), and cleaning activities (including daily vacuuming of the carpet) are carried out before opening in one shift of $3 \mathrm{~h}$. Exhibition development is conditioned by the suitable lightning, heating and cooling of the exhibition area. Energy consumptions were calculated by means of CEX software using building characteristics and location data. A total number of 300,385 visits were registered during 6 months in the first destination of the exhibition. Each visitor spent on average $3.25 \mathrm{~h}$, and an elevated number of visitors (70\%) make use of an audio guide system. It is estimated that the audio-guides were used for $682,500 \mathrm{~h}$ and were loaded around 34,125 times.

The temporary arrangement of the exhibition area involves the construction of a modular walls system with the printed material exposed on them (printed and cut-out vinyl) as well as covering the floor with a polyamide carpet. A total of 415 modules of $1 \times 3 \times 0.2 \mathrm{~m}$ each one, are conveniently distributed in the exhibition area. The structure is made of wood slats, joined by dowels and adhesives and later covered with medium-density fiberboard (MDF) panels. Printed vinyl $\left(372.87 \mathrm{~m}^{2}\right)$ and cut-out vinyl $\left(83.73 \mathrm{~m}^{2}\right)$ are attached in some of these modules. A polyamide carpet thickness $6 \mathrm{~mm}$, fixed with a flooring adhesive, is used to cover the floor in the exhibition hall. To prevent damage during module assembly and painting processes, the carpet includes a plastic protector, which is retired before the inauguration.

The manufacturing process, transport to the exhibition hall and assembly on site of the modular walls system were examined. The sequence of activities performed by the team of carpenters as well as the materials required to the full preparation of the exhibition area was determined (Díez 2019). Data are summarized in Table7. In each destination, dismantling activities after the exhibition was closed were also analysed. Since the current exhibition performance is not based on the reuse of materials in a new location, these are classified into appropriate categories and transported to waste management plants. On the other hand, the transport of artefacts (historical objects and art pieces), showcases, wallcases and frameworks as well as reproductions, facsimiles, models etc. between different destinations is carried out through 110 flying cases and 3 trucks. A total volume of $172.55 \mathrm{~m}^{3}$ and a total weight of $19,600 \mathrm{~kg}$ are transported an average distance of $578.14 \mathrm{~km}$.

Sustainability indicators were evaluated for each system involved. A total of eight destinations are considered. Results obtained, expressed per exhibition visitor, are presented in Table 8 . Values of $0.61 \mathrm{kgCO}_{2}$-eq and $8.44 \mathrm{MJ}$ are, respectively, obtained for the $\mathrm{GWP}_{100}$ and GE indicators of the $\mathrm{P}+\mathrm{S}$ system. Execution costs of $2.36 €$ are calculated. Taking into account that the average ticket price is $8 €$, a value added of $5.67 €$ is obtained. Moreover, accumulated working times and salaries by those workers involved in the $\mathrm{P}+\mathrm{S}$ system development (service providers, workers carrying out the exhibition area layout and transporters) are, respectively, $0.123 \mathrm{~h}$ and $1.205 €$.

Figure 8 shows the relative incidence of different systems and factors on the sustainability indicators of the initial $\mathrm{P}+\mathrm{S}$ system. If the GWP 100 indicator is reviewed (Fig. 8a), we can observe that the relative incidence of $\mathrm{BS}_{1}$ is notably higher than that calculated for other systems. In particular, raw materials used in the exhibition space layout accounts for $61.9 \%$ of the total greenhouse gas emissions. It is mainly because of the large number of MDF panels used in the construction of the modular walls system and the amount of polyamide used to cover the floor. Another factor affecting significantly the $\mathrm{GWP}_{100}$ indicator is the thermal and lighting conditioning of the exhibition area (33.17\%). While, the relative incidence of the transport system $\left(\mathrm{BS}_{2}\right)$ is quite small. If the total costs indicator is reviewed (Fig. 8b), we observe that costs associated with the hired staff along the exhibition performance have the highest impact (70.29\%) and costs due to the use of raw materials in the previous preparation of the exhibition space are also relatively impor$\operatorname{tant}(18.05 \%)$. On the other hand, Fig. 8c shows the percentage distribution of working times between workers involved in the $\mathrm{P}+\mathrm{S}$ system. It is observed that activities involved in the preparation of the exhibition space and transport of material take a relatively small time in the comparison to working hours of the FS employees.

\subsubsection{Application of sustainability strategies}

Strategies to improve $\mathrm{P}+\mathrm{S}$ system sustainability should not compromise its initial specifications. Particularly, the itinerary exhibition requires that the assembly/disassembly activities could be easily carried out in each destination. It is also necessary to keep specific aesthetics giving an illusion of continuity in the exhibition space. From the operational point of view, it is important to ensure appropriate attention to visitors and to guarantee the security of the contents exhibited.

Reviewing the sustainability results obtained in the previous analysis, a significant impact factor is the raw materials used in the exhibition space layout. These materials are discarded after the exhibition finishes at each destination so that a new modular walls system (415 modules) and a new carpet (around $2500 \mathrm{~m}^{2}$ ) have to be manufactured in each location. Thus, the use of a new modular wall system that could be transported and reused in different locations is proposed as a sustainability strategy (strategy 1 ). The new 


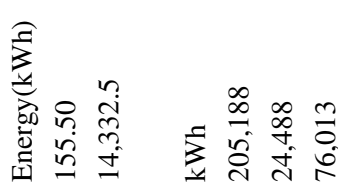

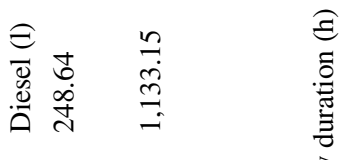

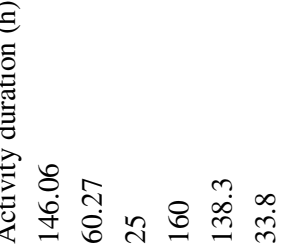

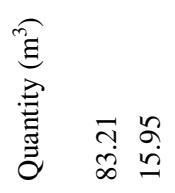

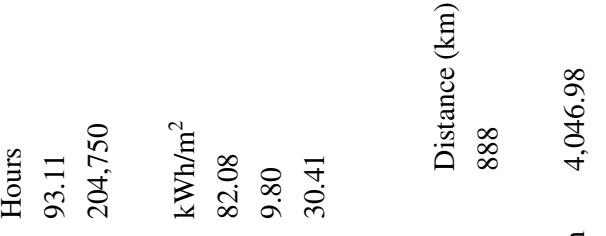

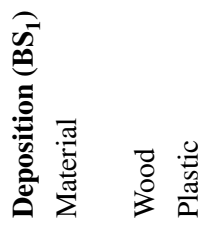

产

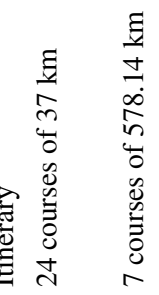

के

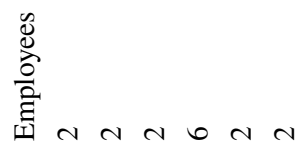

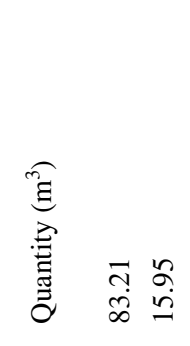

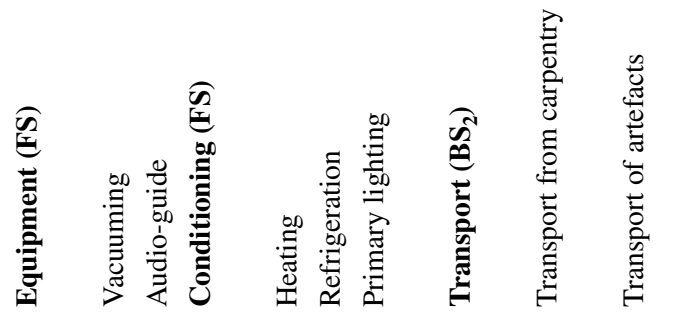

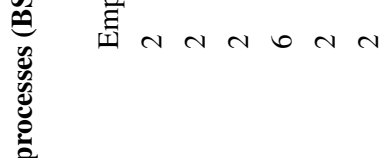

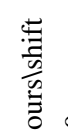

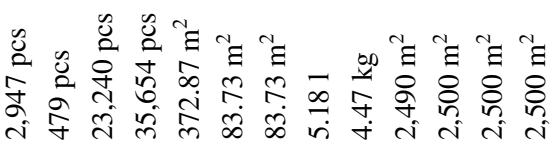

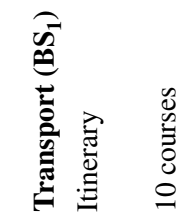

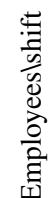

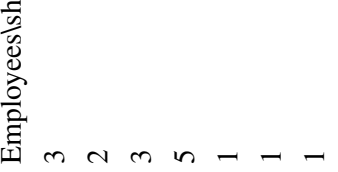

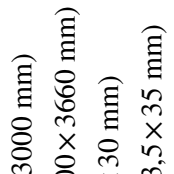

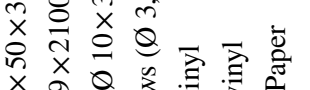

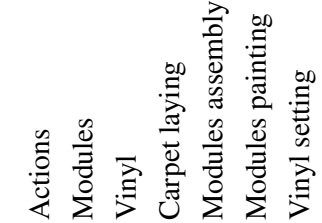

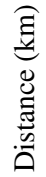

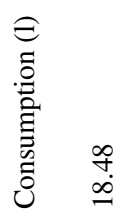

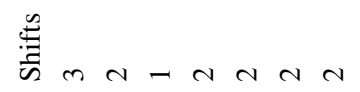

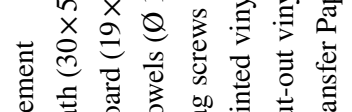

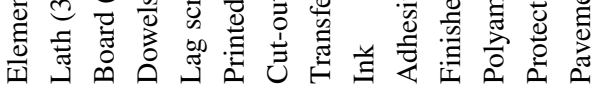

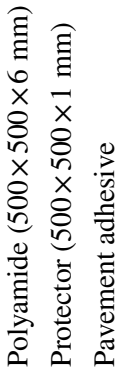

$\stackrel{\Xi}{\exists} \cong$

8

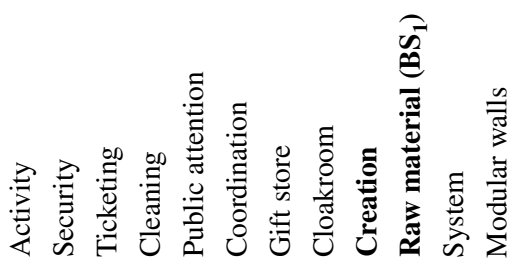

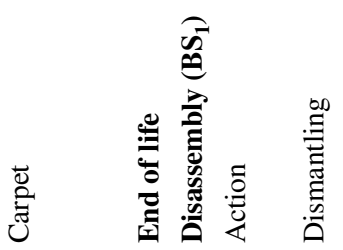


Table 8 Case 2: Itinerary exhibition Sustainability indicators of the initial $\mathrm{P}+\mathrm{S}$ system (data expressed per visit)

\begin{tabular}{|c|c|c|c|c|c|c|}
\hline \multirow[b]{2}{*}{ Initial system } & \multicolumn{2}{|c|}{ Environmental dimension } & \multicolumn{2}{|c|}{ Economic dimension } & \multicolumn{2}{|c|}{ Social dimension } \\
\hline & $\begin{array}{l}\mathrm{GWP}_{100} \\
\left(\mathrm{Kg} \mathrm{CO}_{2} \text {-eq }\right)\end{array}$ & $\begin{array}{l}\text { GE } \\
(\mathrm{MJ})\end{array}$ & $\begin{array}{l}C_{E} \\
(€)\end{array}$ & $\begin{array}{l}\text { VA } \\
(€)\end{array}$ & $\begin{array}{l}\mathrm{T}_{\mathrm{W}} \\
(\mathrm{h})\end{array}$ & $\begin{array}{l}S_{W} \\
(€)\end{array}$ \\
\hline (FS) Service & 0.22 & 3.84 & 1.783 & 5.64 & 0.1151 & 1.143 \\
\hline $\begin{array}{c}\left(\mathrm{BS}_{1}\right) \text { Exhibition } \\
\text { space layout }\end{array}$ & 0.38 & 4.45 & 0.57 & 0.03 & 0.0077 & 0.060 \\
\hline$\left(\mathrm{BS}_{2}\right)$ Transport & 0.009 & 0.13 & 0.01 & 0.0006 & 0.0005 & 0.002 \\
\hline $\mathbf{P}+\mathbf{S}$ & 0.609 & 8.42 & 2.363 & 5.67 & 0.1233 & 1.205 \\
\hline
\end{tabular}

modular wall system consists of standard anodized aluminium profiles assembled with quick joints and covered with two panels made of polyester fabric with a silicone guide in its contour. The fabric will be printed so there will be no need to attach vinyl on it. Since the walls won't be painted and assembly will be done dry, a 3-mm thick carpet made of polyester without a protector is proposed to cover the technical floor. The carpet is fixed with flooring adhesive. Applying this strategy, most of the elements used in the exhibition room preparation can be reused in the following destinations (Fig. 9). Only the carpet and textile panels containing text ( $10 \%$ have to be replaced because of the language change) are newly manufactured in the second and subsequent locations where the exhibition is open. Finally, the appropriate management of different wastes is carried out as the exhibition finishes at the last destination. The total volume of materials, which is required throughout 8 destinations, is greatly reduced from 793.3 to $99.1 \mathrm{~m}^{3}$. Materials can be transported in 2 trucks, which are included in the transport service.

On the other hand, the analysis of the affluence of the visitors revealed that the most visits were taking place on weekends (Friday, Saturday and Sunday-5\%) and the less frequented day was Monday with $5 \%$ of visits, mostly in the afternoon. Only $1.4 \%$ of visits have taken place on Monday morning. Thus, it is proposed to close the exhibition on

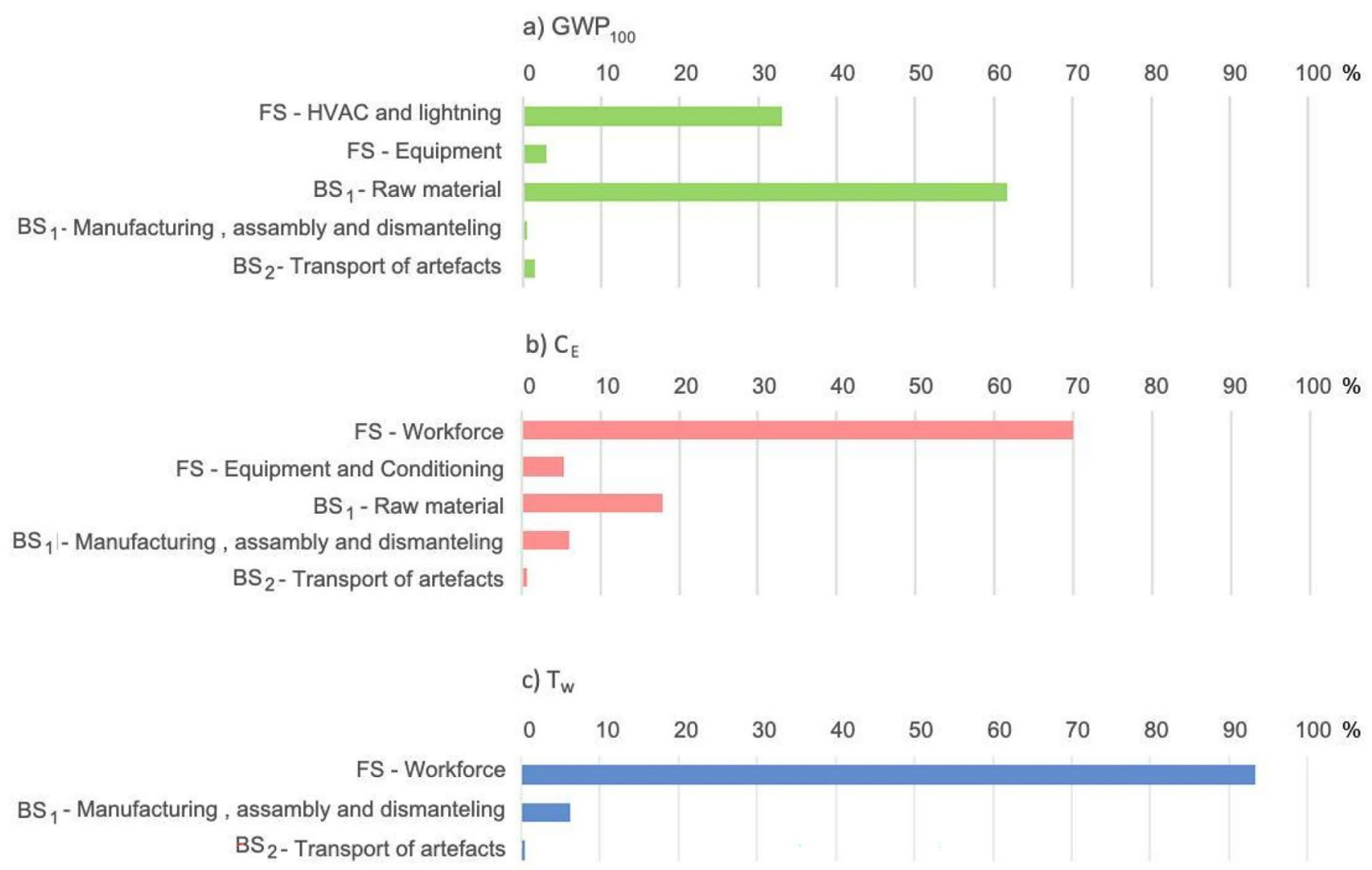

Fig. 8 Case 2: Itinerary exhibition. Percentage distribution of factors affecting sustainability indicators of the initial P+S system 
Fig. 9 Case 2: Itinerary exhibition. Reuse of elements in the exhibition conditioning
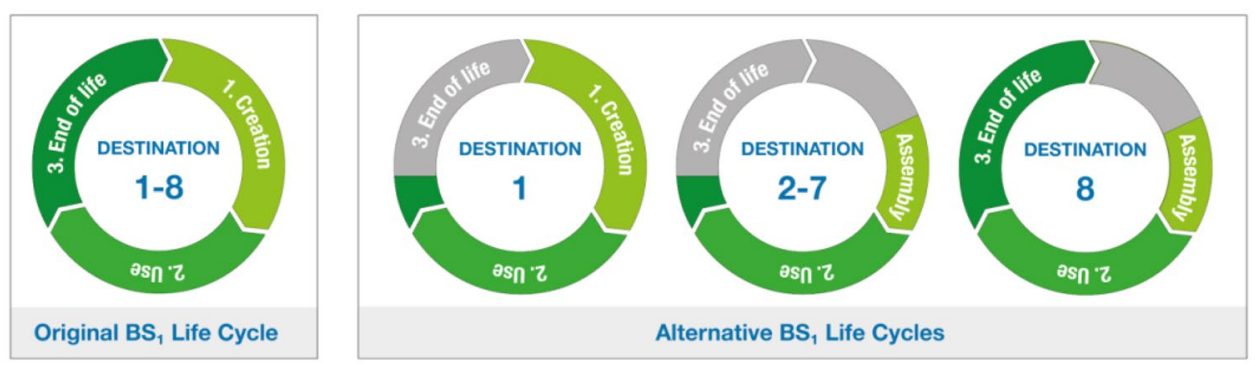

Monday mornings and to transfer Monday morning ticketing to the rest of the week. This strategy aims to reduce energy consumption as well as reduce working times in case of ticketing, public attention, coordination, gift store and cloakroom. The working time of the security and cleaning crew stays unchanged in order to guarantee the same safety and hygiene conditions for both artefacts and the public attending the exhibition.

The evaluation of sustainability indicators for each system was carried out applying the sustainability strategies exposed previously. Results, expressed per visit, are summarized in Table 9. The reuse of the modular wall system considerably affects the impact of $\mathrm{BS}_{1}$, but $\mathrm{BS}_{2}$ indicators are also affected since this new system has to be transported between different destinations. Impacts of $\mathrm{BS}_{2}$ increase, while a substantial improvement is obtained in the environmental indicators of $\mathrm{BS}_{1}$. As a result, environmental indicators of the $\mathrm{P}+\mathrm{S}$ system reduce (approximately 50\%). A significant reduction is also noted in $\mathrm{C}_{\mathrm{E}}(14 \%)$. Variations around $2 \%$ are only obtained in other indicators. On the other hand, as strategy 2 is applied, small changes are detected in sustainability indicators of FS. Reductions of $4.4 \%$ in $\mathrm{T}_{\mathrm{w}}$ and $1.8 \%$ in GE can be noted. A lower environmental impact is not achieved because the thermal conditioning must be assured in the preventive conservation of the contents to exhibit.

If both strategies were simultaneously applied, significant variations could be obtained in the indicators of the $\mathrm{P}+\mathrm{S}$ system. The greenhouse gas emissions decrease from 0.61 to $0.28 \mathrm{KgCO}_{2}$-eq, the execution costs reduce from 2.363 to $2.021 €$ and the working times decrease from 0.123 to $0.113 \mathrm{~h}$. Further study was conducted to know if the proposed strategies could cause improvements in the sustainability of the $\mathrm{P}+\mathrm{S}$ system if different scenarios of itinerary exhibition development are established. In particular, two scenarios, in which some changes affecting exhibition
Table 9 Case 2: Itinerary exhibition Sustainability indicators of the $\mathrm{P}+\mathrm{S}$ system applying sustainability strategies (data expressed per visit)

\begin{tabular}{|c|c|c|c|c|c|c|}
\hline & \multicolumn{2}{|c|}{$\begin{array}{l}\text { Environmental } \\
\text { dimension }\end{array}$} & \multicolumn{2}{|c|}{$\begin{array}{l}\text { Economic } \\
\text { dimension }\end{array}$} & \multicolumn{2}{|c|}{ Social dimension } \\
\hline & $\begin{array}{l}\mathrm{GWP}_{100} \\
\left(\mathrm{Kg} \mathrm{CO}_{2} \text {-eq }\right)\end{array}$ & $\begin{array}{l}\text { GE } \\
(\mathrm{MJ})\end{array}$ & $\begin{array}{l}C_{E} \\
(€)\end{array}$ & $\begin{array}{l}\text { VA } \\
(€)\end{array}$ & $\begin{array}{l}\mathrm{T}_{\mathrm{W}} \\
\text { (h) }\end{array}$ & $\begin{array}{l}S_{W} \\
(€)\end{array}$ \\
\hline & \multicolumn{6}{|l|}{ Strategy 1} \\
\hline (FS) Service & 0.22 & 3.84 & 1.783 & 5.98 & 0.1151 & 1.143 \\
\hline$\left(\mathrm{BS}_{1}\right)$ Exhibition space layout & 0.04 & 0.65 & 0.22 & 0.01 & 0.0025 & 0.019 \\
\hline$\left(\mathrm{BS}_{2}\right)$ Transport & 0.0015 & 0.22 & 0.02 & 0.001 & 0.0008 & 0.003 \\
\hline \multirow[t]{2}{*}{$\mathbf{P}+\mathbf{S}$} & 0,275 & 4,71 & 2,023 & 5,991 & $\mathbf{0 , 1 2}$ & 1,17 \\
\hline & \multicolumn{6}{|l|}{ Strategy 2} \\
\hline (FS) Service & 0.217 & 3.77 & 1.781 & 5,65 & 0.1100 & 1.143 \\
\hline$\left(\mathrm{BS}_{1}\right)$ Exhibition space layout & 0.38 & 4.45 & 0.57 & 0.03 & 0.0077 & 0.060 \\
\hline$\left(\mathrm{BS}_{2}\right)$ Transport & 0.009 & 0.13 & 0.01 & 0.0006 & 0.0005 & 0.002 \\
\hline \multirow[t]{2}{*}{$\mathbf{P}+\mathbf{S}$} & 0,606 & 8,35 & 2,361 & 5,68 & 0,12 & 1,21 \\
\hline & \multicolumn{6}{|c|}{ Strategy $1+$ Strategy 2} \\
\hline (FS) Service & 0.217 & 3.77 & 1.781 & 5.99 & 0.1100 & 1.143 \\
\hline$\left(\mathrm{BS}_{1}\right)$ Exhibition space layout & 0.04 & 0.65 & 0.22 & 0.01 & 0.0025 & 0.019 \\
\hline$\left(\mathrm{BS}_{2}\right)$ Transport & 0.015 & 0.22 & 0.02 & 0.001 & 0.0008 & 0.003 \\
\hline \multirow[t]{2}{*}{$\mathbf{P}+\mathbf{S}$} & 0.272 & 4.64 & 2.021 & 6.001 & 0.1133 & 1.165 \\
\hline & \multicolumn{6}{|c|}{ Strategy $1+$ Strategy 2 in different scenarios } \\
\hline $\mathbf{P}+\mathbf{S}(\mathbf{S} 1)$ & 0.25 & 4.33 & 1.95 & 6.06 & 0.1116 & 1.154 \\
\hline $\mathbf{P}+\mathbf{S}(\mathbf{S 2})$ & 0.32 & 5.30 & 2.06 & 5.95 & 0.1158 & 1.175 \\
\hline
\end{tabular}


destinations, are considered. Scenario 1 (S1) assumes that the number of exhibition destinations reduces to only four cities along a total period of 4 years (the exhibition will be open for 12 months in each location). Scenario 2 (S2) supposes that those cities, in which the opening was initially planned, are changed (taking into account that all are European destinations), so that the distance between destinations increases to four times. Both scenarios assume that the total number of visitors does not change. The resulting $\mathrm{P}+\mathrm{S}$ indicators obtained in each scenario are summarized in Table 9. Results show that the sustainability of the alternative $\mathrm{P}+\mathrm{S}$ system can be considerably affected. If the organization of the itinerary exhibition reduces the number of destinations increasing the opening time (S1), some improvements are noted in sustainability indicators. However, if the changes proposed by the organization entail the increase of the distance between destinations (S2), the positive effect obtained by the sustainability strategies decays. Percentage variations are compared below.

\subsubsection{Comparing sustainability results}

Considerable improvements are obtained in the indicators of the $\mathrm{P}+\mathrm{S}$ system as sustainability strategies are applied. Percentage variations for each involved system are shown in Fig. 10. We observe that a very significant improvement of $\mathrm{BS}_{1}$ indicators is produced because the use of materials is significantly optimized and fewer workforces are required.
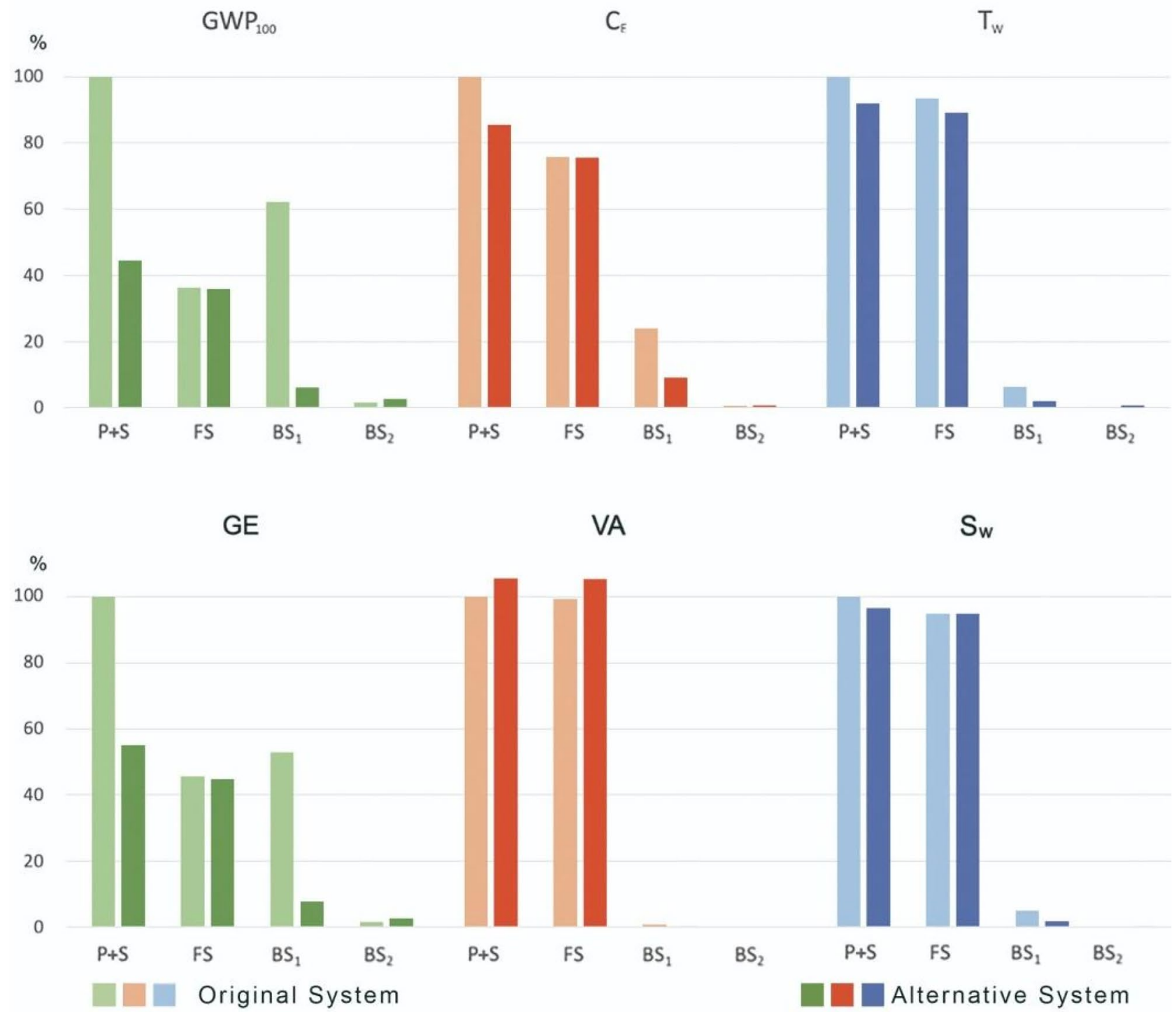

Fig. 10 Case 2: Itinerary exhibition. Comparing sustainability indicators of the initial and alternative $\mathrm{P}+\mathrm{S}$ systems 
The relative improvement in $\mathrm{GWP}_{100}, \mathrm{GE}$ and $\mathrm{T}_{\mathrm{w}}$ indicators are, respectively, 89, 61.4 and $67.5 \%$. Meanwhile, $\mathrm{BS}_{2}$ indicators increase because not only the artefacts will be transported between destinations but also the alternative modular walls system. The relative increase of $\mathrm{BS}_{2}$ indicators is very important in some cases $\left(66,67 \%\right.$ in $\mathrm{GWP}_{100}$ and GE indicators). If FS indicators are reviewed, relative reductions of $1.39,0.12$ and $4.4 \%$ are, respectively, obtained in $\mathrm{GWP}_{100}, \mathrm{C}_{\mathrm{E}}$ and $\mathrm{T}_{\mathrm{W}}$ indicators. These variations detected in each system give rise to significant variations in the indicators of the $\mathrm{P}+\mathrm{S}$ system. $\mathrm{GWP}_{100}$ and GE reduce, respectively, 54.5 and $44.8 \%$. A significant reduction of $14.4 \%$ is calculated for the $\mathrm{C}_{\mathrm{E}}$, while an increase of 5.6\% is calculated for VA. In the social dimension, $\mathrm{T}_{\mathrm{W}}$ and $\mathrm{S}_{\mathrm{W}}$ reduce 8.1 and $3.3 \%$, respectively. Therefore, strategies can be considered effective to improve sustainability of the $\mathrm{P}+\mathrm{S}$ system, especially in the case of the strategy 1 , which affects $\mathrm{BS}_{1}$ (with a high relative incidence in the $\mathrm{P}+\mathrm{S}$ system).
The sustainability of the alternative $\mathrm{P}+\mathrm{S}$ system is also analysed establishing two different scenarios (S1 and S2), in which the itinerary exhibition could be developed. Figure 11 shows results obtained in both cases. Percentage variations of sustainability indicators are comparatively expressed considering the contribution of each system involved. Thus, changes in the incidence of BSs can be noted. We observe that the most positive results are obtained if the alternative $\mathrm{P}+\mathrm{S}$ system is developed in the $\mathrm{S} 1$ conditions. In this case, the impact of both $\mathrm{BS}_{1}$ and $\mathrm{BS}_{2}$ reduces. This positive effect adds to the already achieved applying strategy 1 , so that improvements of 58.4, 17.3 and $9.4 \%$ are, respectively, achieved in $\mathrm{GWP}_{100}, \mathrm{C}_{\mathrm{E}}$ and $\mathrm{T}_{\mathrm{W}}$ with respect to the initial $\mathrm{P}+\mathrm{S}$ system. $\mathrm{T}_{\mathrm{W}}$ can be improved because working times in both transport service and assembly/disassembly activities associated with the preparation of the exhibition area significantly reduce. Therefore, this scenario in which the
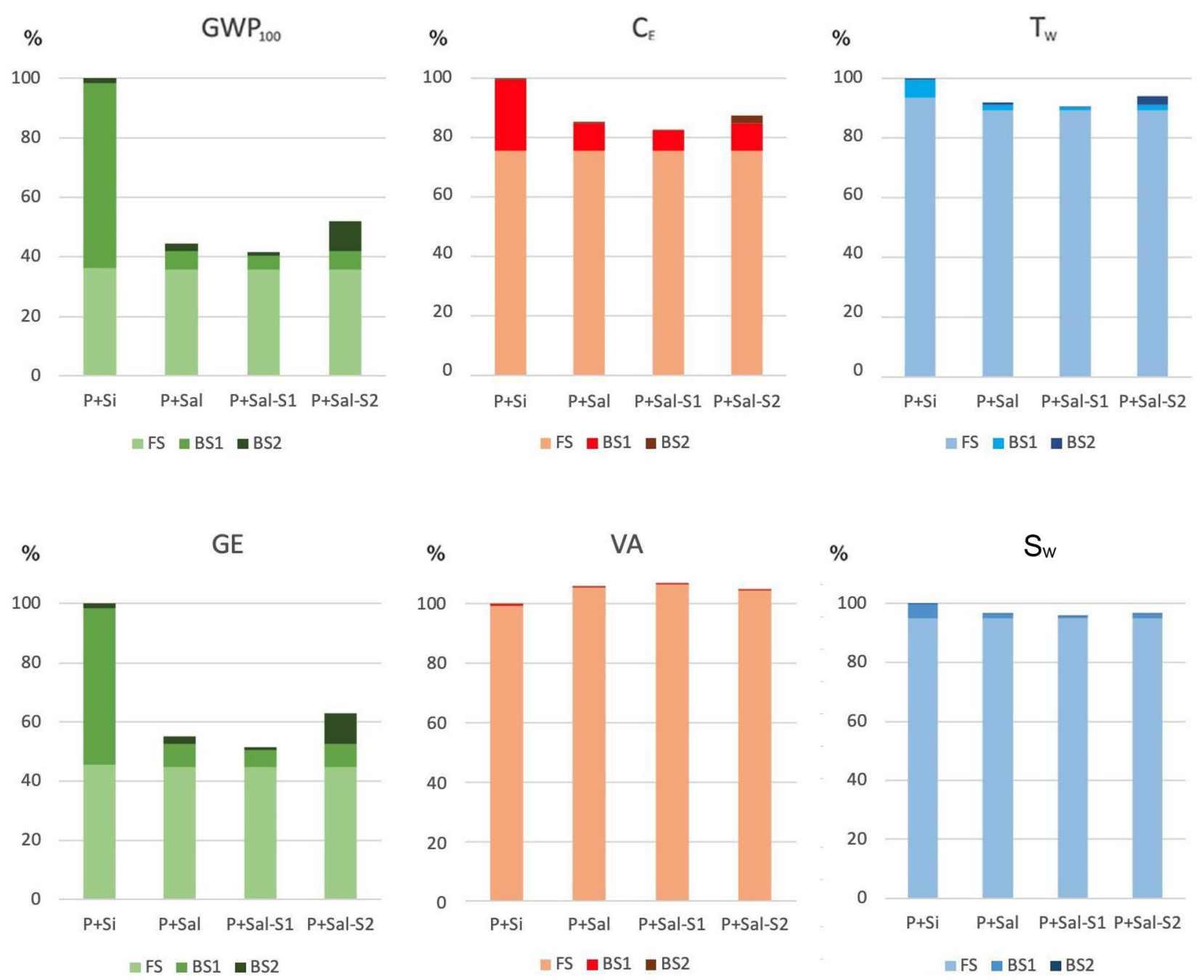

Fig. 11 Case 2: Itinerary exhibition. Comparing sustainability indicators of the $\mathrm{P}+\mathrm{S}$ system considering different scenarios 
development of the itinerary exhibition happens in fewer destinations and with opening longer periods at each destination is favourable to improve its sustainability.

On the other hand, if the alternative $\mathrm{P}+\mathrm{S}$ system is developed in the $\mathrm{S} 2$ conditions, a negative effect is detected. The percentage contribution of $\mathrm{BS}_{2}$ increases, so that a higher impact is estimated in environmental indicators, as well as in $\mathrm{C}_{\mathrm{E}}$ and $\mathrm{T}_{\mathrm{W}}$ indicators. Nonetheless reductions of 47.92 , 12.51 and $6.08 \%$ are, respectively, obtained in $\mathrm{GWP}_{100}, \mathrm{C}_{\mathrm{E}}$ and $\mathrm{T}_{\mathrm{W}}$ indicators with respect to the initial $\mathrm{P}+\mathrm{S}$ system. This unfavourable scenario, in which the distance between destinations is considerably increased, allows us testing the efficiency of the strategies proposed to improve the sustainability of the system under study and providing criteria to carry out sustainability-oriented decision making.

\section{Conclusions}

Methods to achieve sustainability improvements in product systems have been already developed and implemented along the last decades. However, much of the production and consumption activities are based on the development of more complex systems composed of products and services $(\mathrm{P}+\mathrm{S}$ systems). In this work, an approach that contributes to project more sustainable $\mathrm{P}+\mathrm{S}$ systems has been developed. The integration of different methods and tools has been carried out to properly describe them, to achieve a quantitative sustainability assessment with a life cycle perspective, to apply effective sustainability strategies and to analyse both individual and global effects of strategic decisions.

A methodological scheme organized in four phases has been applied. First, the identification of different systems (FS and BSs) and their specific connections is carried out. Next, sustainability of each system is evaluated taking into account environmental and socio-economic aspects. In addition, the relative incidence of each system and the most significant impact factors are determined. Then, different strategies to achieve sustainability improvements are applied. Finally, sustainability indicators of both initial and alternative $\mathrm{P}+\mathrm{S}$ systems are compared to value the effects of each strategy.

This approach with a clear and defined structure, has been implemented in two different $\mathrm{P}+\mathrm{S}$ systems, in which FS are, respectively, a service dedicated to selling clothes in the centre of a big city and a cultural service, in which historical themes are temporarily exhibited in different destinations. In the first case, the clothes commercialized and the store in which the service is developed are product systems involved in the $\mathrm{P}+\mathrm{S}$ system. In the second case, the exhibition space layout and the transport service to carry all materials between destinations are also considered. Thus, the involved systems have been identified, and the scope of the study has been defined applying the first phase of the method.

In the second phase, sustainability of the $\mathrm{P}+\mathrm{S}$ systems has been assessed using LCSA methodology. Sustainability indicators have been expressed using FU, which is referred to the FS established in each case. Thus, the relative incidence of each system in the sustainability of the $\mathrm{P}+\mathrm{S}$ system has been determined providing suitable criteria to project more sustainable alternatives. In addition, indicators of different sustainability dimensions have been evaluated, providing data hardly found in research works, usually focused only on one or two sustainability dimensions. The 10 Consensus Principles of the LCSA (Valdivia et al. 2021) establish a practical harmonization to promote the use of this methodology. While the application of some of these principles has been already achieved in this study (alignment with ISO 14040, materiality of the system boundaries, consistency and transparency), the application of other principles has been limited, and its progressive incorporation represents a challenge for the future studies in which the sustainability assessment of $\mathrm{P}+\mathrm{S}$ systems was addressed. Besides the workers' category, social demands of customers are being currently analysed in order to take into consideration the perspectives of key stakeholders.

The challenge of proposing sustainability strategies taking into account the three sustainability dimensions is carried out in the third phase. In the clothing boutique case, strategies such as the reduction of clothes acquired by the service provider and changes in furniture design and distribution are planned. In the second case study, one of the improvement strategies is focused on the design of a new wall system for the temporary arrangement of the exhibition area, which could be reused in each different location where the exhibition will be developed. Sustainability indicators of alternative $\mathrm{P}+\mathrm{S}$ systems are evaluated and variations due to the interconnection of systems are detected.

Finally, the effects of applying sustainability strategies are analysed through the parallel comparison of indicators and the use of an aggregated sustainability index. Substantial improvements are found in the clothing boutique case if the amount of clothes acquired by the service provider to the textile industry reduces. Changes in furniture design and distribution allows reducing the working time of the service providers. If both strategies are combined, the global $\mathrm{P}+\mathrm{S}$ system sustainability is improved even considering different weight coefficients for each sustainability dimension. In the itinerary exhibition case, the application of strategies also supposes a positive effect on the $\mathrm{P}+\mathrm{S}$ sustainability, especially if the strategy consisting in reuse of the walls system can be implemented. Both positive and negative effects are, respectively, detected in the exhibition space layout and the transport service, but the global $\mathrm{P}+\mathrm{S}$ sustainability is improved, even if different scenarios are considered. 
In both cases, the application of the approach proposed has been useful and effective to project sustainability improvements in complex systems composed of products and services. Considerable effort has been devoted to the identification of interconnections between systems involved and the determination of its relative incidence in the global $\mathrm{P}+\mathrm{S}$ sustainability. Nevertheless, the number of systems, which have been analysed in each case, has been limited. In the same way, the sustainability study of the social dimension has been only based on the workers' category. In order to apply appropriate sustainability strategies, a wider number of systems should be included in the study, and the impacts of other key stakeholder categories should be also considered. The analysis of extensive interconnected systems and the selection and evaluation of appropriate indicators associated with different stakeholder categories are significant challenges for the researchers.

In addition, the simultaneous improvement of the three sustainability dimensions is not achieved in all cases in which sustainability strategies are applied. In these cases, the use of a global sustainability index can be a practical method to value the convenience of the strategy applied, and weights assigned to each sustainability dimension will be determinant to consider if a final improvement is obtained. Different weights can be established according to the preferences of the decision makers, so it is desirable the application of harmonized criteria as well as the use of suitable multi-criteria decision making methods to determine the result of the strategies implemented. Further investigations should be carried out not only to implement sustainability strategies in a wider number of complex systems currently in operation but on the elaboration of a suitable methodology to design new sustainable $\mathrm{P}+\mathrm{S}$ systems.

Funding Open Access funding provided thanks to the CRUE-CSIC agreement with Springer Nature. Research project of the University of Zaragoza UZ2020-TEC-02: PLANTEAMIENTO DE UNA METODOLOGÍA DE DISEÑO SOSTENIBLE EN SISTEMAS PRODUCTO-SERVICIO, and research project founded by Gobierno de Aragón - Sostenibilidad de Servicios y Productos Culturales. Desarrollo de una Metodología de Diseño Multidimensional.

Data availability statement The datasets analysed during the current study are available from the corresponding author on reasonable request.

\section{Declarations}

Conflict of interests The authors declare no competing interests.

Open Access This article is licensed under a Creative Commons Attribution 4.0 International License, which permits use, sharing, adaptation, distribution and reproduction in any medium or format, as long as you give appropriate credit to the original author(s) and the source, provide a link to the Creative Commons licence, and indicate if changes were made. The images or other third party material in this article are included in the article's Creative Commons licence, unless indicated otherwise in a credit line to the material. If material is not included in the article's Creative Commons licence and your intended use is not permitted by statutory regulation or exceeds the permitted use, you will need to obtain permission directly from the copyright holder. To view a copy of this licence, visit http://creativecommons.org/licenses/by/4.0/.

\section{References}

Álvarez-Rodríguez C, Martín-Gamboa M, Iribarren D (2019) Combined use of Data Envelopment Analysis and Life Cycle Assessment for operational and environmental benchmarking in the service sector: A case study of grocery stores. Sci Total Environ 667:799-808

Amaya J, Lelah A, Zwolinski P (2014) Design for intensified use in product-service systems using life-cycle analysis. J Eng Des 25:7-9

Andriankaja H, Vallet F, Le Duigou J, Eynard B (2015) A method to ecodesign structural parts in the transport sector based on product life cycle management. J Clean Prod 94:165-176

Arias A, Rama M, González-García S, Feijoo G, Moreira MT (2020) Environmental analysis of servicing centralised and decentralised wastewater treatment for population living in neighbourhoods. J Water Process Eng 37:101469

Arzoumanidis I, Raggi A, Petti L (2019) Life Cycle Assessment of Honey: Considering the Pollination Service. Adm Sci 9:27

Ashford NA, Hall RP (2011) The importance of Regulation-Induced Innovation for Sustainable Development. Sustainability 3:270-292

Aurich JC, Fuchs C, Wagenknecht C (2006) Life cycle oriented design of technical product-service systems. J Clean Prod 14(17):1480-1494

Azapagic A, Stamford L, Youds L, Barteczko-Hibbert C (2016) Towards sustainable production and consumption: a novel decision-support framework integrating economic, environmental and social sustainability (DESIRES). Comput Chem Eng 91:93-103

Baden D, Prasad S (2016) Applying behavioural theory to the challenge of sustainable development: using hairdressers as diffusers of more sustainable hair-care practices. J Bus Ethics 133:335-349

Bech NM, Birkved M, Charnley F, Kjaer LL, Pigosso DCA, Hauschild MZ, McAloone TC, Moreno M (2019) Evaluating the Environmental Performance of a Product/Service-System Business Model for Merino Wool Next-to-Skin Garments: The Case of Armadillo Merino. Sustainability 11:5854

Boehm M, Thomas O (2013) Looking beyond the rim of one's teacup: a multidisciplinary literature review of product-service systems in information systems, business management, and engineering design. J Clean Prod 51:245-260

Bovea MD, Pérez-Belis V (2012) A taxonomy of eco-design tools for integrating environmental requirements into the product design process. J Clean Prod 20(1):61-71

Brezet JC, Van Hemel CG (1997) Ecodesign: a promising approach to sustainable production and consumption. United Nations Publications, Paris, UNEP

Brezet JC, Bijma AS, Ehrenfeld J, Silvester S (2001) The design of eco-efficient services. TU Delft for the Dutch Ministry of Environment, Delft, Netherlands

Buchert T, Kaluza A, Halstenberg FA, Lindow K, Hayka H, Stark $R$ (2014) Enabling product development engineers to select and combine methods for sustainable design. Procedia CIRP $15: 413-418$ 
Casson A, Giovenzana V, Tugnolo A, Fiorindo I, Beghi R, Guidetti R (2020) Environmental impact of a new concept of food service: A case study for the re-use of naval shipping containers. J Clean Prod 274:122912

Ceschin F, Gaziulusoy I (2016) Evolution of design for sustainability: from product design to design for system innovations and transitions. Des Stud 47:118-163

Crul M, Diehl JC (2009) Design for sustainability. United Nations Environment Programme (UNEP), United Nations Publications, Paris, A step-by-step approach

Da Costa S, Pigosso D, McAloone T (2020) Towards product-service system oriented to circular economy: systematic review of value proposition design approaches. J Clean Prod 257

Del Borghi A, Strazza C, Gallo M, Messineo S, Naso M (2013) Water supply and sustainability: life cycle assessment of water collection, treatment and distribution. Int J Life Cycle Assess 18:1158-1168

Díez O (2019) Estudio de la sostenibilidad aplicada al diseño de una exposición itinerante. University of Zaragoza, Final Degree Project

Doualle B, Medini K, Boucher X, Laforest V (2015) Investigating sustainability assessment methods of product-service systems. Procedia CIRP 30:161-166

Duane B, Taylor T, Stahl-Timmins W, Hyland J, Mackie P, Pollard A (2014) Carbon mitigation, patient choice and cost reduction - triple bottom line optimisation for health care planning. Public Health 128:920-924

EN 15804:2012+A2:2019 (2019) Sustainability of construction works - Environmental product declarations - Core rules for the product category of construction products. CEN/TC: Brussels, Belgium, 2019

EPD (2020) Database 2020 [Online] www.environdec.com/EPDSearch/. Accessed Feb 2020

Farreny R, Oliver J, Escuder S, Roca M, Sevigné E, Gabarrell X, Rieradevall J (2012) The metabolism of cultural services. Energy and water flows in museums. Energ Buildings 47:98-106

Fauzi RT, Lavoie P, Sorelli L, Heidari MD, Amor B (2019) Exploring the current challenges and opportunities of Life Cycle Sustainability Assessment. Sustainability 11:636

Fiksel JR (1996) Design for Environment: Creating Eco-efficient Products and Processes. McGraw-Hill, New York

Finkbeiner M, Schau EM, Lehmann A, Traverso M (2010) Towards Life Cycle Sustainability Assessment Sustainability 2(10):3309-3322

Gagnon B, Leduc R, Savard L (2012) From a conventional to a sustainable engineering design process: different shades of sustainability. J Eng Des 23(1):49-74

Gan X, Fernández IC, Guo J, Wilson M, Zhao Y, Zhou B, Wu J (2017) When to use what: Methods for weighting and aggregating sustainability indicators. Ecol Ind 81:491-502

Goedkoop M, Heijunngs R, Huijbregts M, Schryver A, Struijs J, Van Zelm R (2013) ReCiPe 2008. A life cycle impact assessment method which comprises harmonized category indicators at the midpoint and the endpoint level. PRé Consultants, Amersfoort. The Netherlands

Gómez N, Cadarso MA, Monsalve F (2016) Carbon footprint of a university in a multiregional model: the case of the University of Castilla-La Mancha. J Clean Prod 138:119-130

Huijbregts M, Steinmann Z, Elshout P, Verones F, Vieira M, Hollander A, Zijp M, Van Zelm R, Stam G (2016) ReCiPe 2016. A harmonized life cycle impact assessment at midpoint and endpoint level. Report I: Characterization. National Institute for Public Health and the Environment. The Netherlands

ISO (2006a) ISO 14040 International Standard. In: Environmental management - Life cycle assessment - Principles and framework. International Organisation, Geneva, Switzerland
ISO (2006b) ISO 14040 International Standard. In: Environmental management - Life cycle assessment - Requirements and Guidelines. International Organisation, Geneva, Switzerland

International Trade Union Confederation (ITUC) Frontlines Report (2016) End Corporate Greed. Belgium, Brussels

Kloepffer W (2008) Life cycle sustainability assessment of products (with comments by Helias A. Udo de Haes, p. 95). Int J Life Cycle Assess 13(2):89-95

Lacasa E, Santolaya JL, Biedermann A (2016) Obtaining sustainable production from the product design analysis. J Clean Prod 139:706-716

Liu G, Agostinho F, Duan H, Song G, Wang X, Giannetti BF, Santagata R, Casazza M, Lega M (2020) Environmental impacts characterization of packaging waste generated by urban food delivery services. A big-data analysis in Jing-Jin-Ji region (China). Waste Manage 117:157-169

Mapama (2018) Spain Government. [Online] www.miteco.gob.es/ es/cambio-climatico/temas/mitigacion-politicas-y-medidas/ factores_emision_tcm30-446710.pdf

Maxime D, Marcotte M, Arcand Y (2006) Development of ecoefficiency indicators for the Canadian food and beverage industry. J Clean Prod 14:636-648

Muñoz N, Santolaya JL, Biedermann A, Serrano A (2020) Sustainability Assessment of Product-Service Systems using flows between systems approach. Sustainability 12(8):3415

Nazar H, Nazar Z (2019) Community pharmacy minor ailment services: Pharmacy stakeholder perspectives on the factors affecting sustainability. Res Social Adm Pharm 15:292-302

Neugebauer S, Martinez-Blanco J, Scheumann R, Finkbeiner M (2015) Enhancing the practical implementation of life cycle sustainability assessment: Proposal of a Tiered approach. J Clean Prod 102:165-176

Nurhadi L, Borén S, Ny H, Larsson T (2017) Competitiveness and sustainability effects of cars and their business models in Swedish small town regions. J Clean Prod 140:333-348

OECD (2008) Handbook on Constructing Composite Indicators: Methodology and User Guide. OECD publishing

Ryan CJ, Hosken M, Greene D (1992) EcoDesign: Design and the response to the greening of the international market. Des Stud 13(1):3-22

Santolaya JL, Lacasa E, Biedermann A, Muñoz N (2019) A practical methodology to project the design of more sustainable products in the production stage. Res Eng Des 30(4):539-558

Scheepens AE, Vogtländer JG, Brezet JC (2016) Two life cycle assessment (LCA) based methods to analyse and design complex (regional) circular economy systems. Case: making water tourism more sustainable. J Clean Prod 114:257-268

Sousa-Zomer TT, Cauchick PA (2018) Sustainable business models as an innovation strategy in the water sector: An empirical investigation of a sustainable product-service system. J Clean Prod 171:119-129

Sun H (2010) Product service relationship: defining, modelling and evaluating. Int J Internet Manuf Serv 2(2):128-141

Tukker A (2015) Product services for a resource-efficient and circular economy - a review. J Clean Prod 97 (76-91)

UBA (2007) Umweltbundesamt (UBA). German Environmental Protection Agency

UNCED (1992) Agenda 21, United Nations Conference on Environment and Development, Rio de Janeiro, June 1992

UNEP (2020) Guidelines for Social Life Cycle Assessment of Products and Organizations 2020. Benoît Norris, C., Traverso, M., Neugebauer, S., Ekener, E., Schaubroeck, T., Russo Garrido, S., Berger, M., Valdivia, S., Lehmann, A., Finkbeiner, M., Arcese, G. (eds.). United Nations Environment Programme (UNEP)

United Nations Environment Programme (UNEP) (2015) Using product-service systems to enhance sustainable public procurement, 
[Online] http://www.unep.org/10yfp/Portals/50150/10YFP\% 20SPP/3A_Technical\%20report.pdf. Accessed August 2015

Valdivia S, Backes JG, Traverso M et al (2021) Principles for the application of life cycle sustainability assessment. Int $\mathbf{J}$ Life Cycle Assess 26:1900-1905. https://doi.org/10.1007/ s11367-021-01958-2

Valdivia S, Ugaya CML, Hildenbrand J, Traverso M, Mazijn B, Sonneman G (2013) A UNEP/SETAC approach towards a life cycle sustainability assessment-our contribution to Rio+20. Int J Life Cycle Assess 18:1673-1685

Van Halen C, Vezzoli C, Wimmer R (2005) Methodology for product service systems. How to develop clean, clever and competitive strategies in companies. Van Gorcum, Assen, Netherlands

Vezzoli C, Kohtala C, Srinivasan A (2014) Product-service system design for sustainability. Greenleaf Publishing, Sheffield, UK

Villoria P (2014) Management system for construction and demolition waste in residential construction works. Good practices in construction sites ( $\mathrm{PhD}$ thesis). Polytechnic University of Madrid
Vogtlander JG, Scheepens AE, Bocken NM, Peck D (2017) Combined analyses of costs, market value and eco-costs in circular business models: Eco-efficient value creation in remanufacturing. $\mathrm{J}$ Remanufacturing 7(1):1-17

WCED (World Commission on Environment and Development) (1987) Our common future. Oxford University Press

Wimmer W, Züst R (2003) Ecodesign PILOT: Product Investigation. Kluwer Academic Publishers, Dordrecht, Learn Optim Tool Sustain Product Dev

Wulf C, Werker J, Ball C, Zapp P, Kuckshinrichs W (2019) Review of Sustainability Assessment Approaches Based on Life Cycles. Sustainability 2019(11):5717

Zheng X, Easa SM, Yang Z, Ji T, Jiang Z (2019) Life-cycle sustainability assessment of pavement maintenance alternatives: Methodology and case study. J Clean Prod 213:659-672

Publisher's Note Springer Nature remains neutral with regard to jurisdictional claims in published maps and institutional affiliations. 